\title{
RESURRECCIÓN Y RECREACIÓN DE DAFNIS Y CLOE EN LA EDAD DE PLATA (1868-1936): MORAL, FILOLOGÍA Y ESPACIO LITERARIO ${ }^{1}$
}

\author{
Pilar Hualde Pascual \\ Universidad Autónoma de Madrid
}

\section{RESUMEN}

El trabajo pretende rastrear los ecos que la novela griega Dafnis y Cloe ha dejado en diversos autores de la Edad de Plata de la cultura española, partiendo de una recopilación cronológica y de una interpretación crítica de los datos. De esta manera se intentará demostrar que, a partir de la traducción de Juan Valera, algunos escritores de finales del XIX recurren a la mención de los personajes de la novela de Longo como mero recurso estético impuesto por la moda, mientras que otros buscan en su trama la inventio del asunto de sus novelas. Intentaremos demostrar, asimismo, que ciertos autores, pertenecientes ya a las generaciones del 98 y del 14, con una formación mayor o menor en la lengua griega, redescubren Las Pastorales y las utilizan para polarizar en torno a ellas sus ideas respecto a la sexualidad, en el marco de la llamada novela lírica. Finalmente se observará la recurrencia a Dafnis y Cloe en determinados escritores de la generación del 27 ya con una función simbólica, ya para deconstruir un clásico introduciéndolo en la estética de la modernidad.

Palabras clave: Novela Griega, Edad de Plata, Tradición Clásica, Dafnis y Cloe.

\section{RESURRECTION AND RECREATION OF DAPHNIS AND CHLOE IN THE SPANISH SILVER AGE (1868-1936): MORAL, PHILOLOGY AND LITERARY SPACE}

\begin{abstract}
The aim of this paper is to search for the impact that the Greek novel Daphnis and Chloe had in several authors of the Silver Age of the Spanish culture, on the basis of a chronological compilation and critical interpretation of the data. In this way, this paper will try to demonstrate that, from the time of Juan Valera's translation onwards, some writers of the late 19th century resort to mentioning the characters of Longus' novel as a mere aesthetic resource imposed by fashion, while others look at its plot to find the inventio of the subject of their novels. Also, this paper will try to demostrate that certain authors, belonging already to the Generations of ' 98 and '27 and with more or less knowledge of Greek, rediscover Las Pastorales and use them to polarize

${ }^{1}$ Este trabajo se inserta en el Proyecto de Investigación Historiografía de la Literatura grecolatina en España: La «Edad de Plata» (1868-1936) MEC HUM2007-60326/FILO, su autora es miembro del Grupo Complutense de Investigación 930136 Historiografía de la Literatura grecolatina en España.
\end{abstract}


their opinions about sexuality, in the framework of the so-called lyric novel. Finally, the paper will highlight the resort to Daphnis and Chloe made by certain writers of the Generation of '27, either with a symbolic function, either to deconstruct a classic by introducing it into the aesthetics of modernity.

Key words: Greek novel, Silver Age, Classical Tradition, Daphnis and Chloe.

\section{Cuestiones PREVIAS. Redescubrimiento DE LA NOVELA GRIEGA EN EUROPA Y EN ESPAÑA}

No cabe ninguna duda de que el género estrella de la literatura decimonónica es la novela. Para el estudio de la literatura de una época en que surge el Realismo, de un momento en que se debaten en suelo patrio los ecos del Naturalismo francés, en un contexto en que triunfa el folletín, podemos preguntarnos qué peso han tenido en la génesis y desarrollo de la novela española del momento los ya lejanos ejemplos fundacionales del género novelístico, es decir, la novela griega. En este trabajo, vamos a llevar a cabo un estudio de la presencia de una novela griega, Dafnis o Cloe, también llamada Las Pastorales de Longo de Lesbos, en la literatura española desde los últimos decenios del siglo XIX a 1936, partiendo de una recopilación cronológica y de una interpretación crítica de los datos encontrados.

En una España siempre retrasada, marcada por las guerras que jalonan su siglo XIX, y poco permeable a novedades foráneas, hay que mirar muy hacia atrás para encontrar una época de cierta eclosión de la novela clásica y de su pervivencia en las letras españolas. En efecto, el redescubrimiento de los escasos ejemplares de novela griega conservados por parte de la Europa del siglo XVI permitió que en buena medida se configurara el género novelesco en occidente según las claves de la novela griega de amor y aventuras, y, en este caso, España no fue ajena a dicha moda literaria. Sin embargo, de las tres novelas griegas que más influyeron en las literaturas occidentales, Leucipa y Clitofonte de Aquiles Tacio (s. II d.C.), Dafnis y Cloe de Longo de Lesbos (s. II d.C.) y Las Etiópicas de Heliodoro de Émesa (s. IV d.C.), sólo dos, Leucipa y Clitofonte y Las Etiópicas, tuvieron tempranas versiones al español ${ }^{2}$, lo que posibilitó su influencia en determinados géneros de la literatura

${ }^{2}$ Desde luego, pese a lo meritorio que resulta el haber dotado a las letras patrias de versiones de los novelistas antiguos, lógicamente, la no muy abundante formación de intelectuales en las letras griegas en este momento, hace que, en su mayoría, las versiones se reproduzcan a partir de traducciones al francés, al italiano o al latín, en el mejor de los casos, si bien con el texto griego a la vista. Así, para el caso de Heliodoro, contamos con una primera traducción anónima hecha en Amberes por alguien cercano a los círculos erasmistas españoles, en 1554, con segunda impresión en Alcalá de Henares en 1585 y otra publicada en Toledo 1563, reproducción de la primera, pero con distinto prólogo, en la que se declara falsamente que ha sido traducida directamente de la lengua griega (para las cir- 
patria del Siglo de Oro, y, en definitiva, en la gestación del género novelesco en nuestro país, a través de la «novela bizantina», denominada así durante muchos años, si bien hoy los especialistas prefieren llamar a estas obras «libros de aventuras peregrinas».

Sin embargo, la obra de Longo, cuyas tempranas versiones a distintas lenguas europeas la convirtieron en una de las más influyentes novelas griegas en la formación del género en las literaturas modernas ${ }^{3}$, continuaba sin traducción al español en el último cuarto del siglo XIX. De esta manera, mientras que la novela de Aquiles Tacio y la de Heliodoro, por sus traducciones españolas del XVI y XVII, tuvieron gran recepción en las letras hispanas desde el Siglo de Oro, Dafnis y Cloe permanecía desconocida para todo aquel que no tuviese acceso a las restantes versiones europeas, especialmente a la francesa del obispo $\mathrm{Amyot}^{4}$, que fue la que mayor difusión tuvo. No cabe duda de que las escenas explícitamente eróticas de la novela de Longo tenían mayor dificultad para ser eludidas que los pasajes amorosos más ocasionales de las obras de Aquiles Tacio y de Heliodoro.

2. LA LLEGADA DEL XIX: CONSIDERACIÓN DE LA NOVELA EN LOS ESTUDIOS DE LITERATURA GRIEGA DE LA ÉPOCA. LA NOVELA GRIEGA ENTRA EN EL DEBATE ESTÉTICO

Frente al prestigio, la novedad y la condición de modelo que las Etiópicas y Leucipa y Clitofonte tienen en España en los siglos XVI, XVII y aún en el XVIII, el siglo XIX las destituye de su canon estético. Esta es la causa de que dejen de reeditarse las traducciones de Fernando de Mena o de Diego de Agreda y Vargas, que habían brillado en las letras patrias de las centurias

$\overline{\text { cunstancias de }}$ esta edición desconocida. Cf. GONZÁLEZ ROVIRA, Javier. «Una edición olvidada de Teágenes y Cariclea de Heliodoro». Boletín de la Biblioteca Menéndez Pelayo, 1995, LXXI, pp. 17-24.) Pero la más famosa es, sin duda la realizada por Fernando de Mena, publicada en Alcalá de Henares en 1587 y realizada asimismo sobre la versión latina de Warschewiczki, pero cotejándola con el texto griego. Respecto a Aquiles Tacio, España contó con la temprana versión de Diego de Agreda y Vargas, que ve la luz en 1617 y está realizada sobre la italiana (de F. A. Coccio, 1551) y, según palabras del prólogo, «traducida, censurada y parte compuesta». Para los detalles de esta versión y su censura de aspectos eróticos del original, así como de introducción de elementos moralizantes. Cf. RUIZ CASADO, Antonio. «Diego de Agreda y Vargas. Traductor de Aquiles Tacio (1617)». En: PAREDES NÚÑEZ, Juan; SORIA OLMEDO, Andrés (eds.). Actas del VI Simposio de Literatura General y Comparada. Granada: Publicaciones de la Universidad de Granada, 1989, pp. 285-92.

${ }^{3}$ Cf. HUALde PASCUAL, Pilar. «Longo. Dafnis y Cloe». En HUALDE, Pilar; SANZ, Manuel (eds). La Literatura Griega y su Tradición. Madrid: Akal, 2008, p. 361-389.

${ }^{4}$ Les amours pastorales de Daphnis et Chlóe, escrites en grec par Longus, et translatées en françois par Jacques Amyot. Paris: pour Vicent Sertenas, 1559. 
anteriores ${ }^{5}$. Este estado de cosas se refleja en la consideración que del género de la novela se hace en los primeros manuales de literatura griega publicados en España ${ }^{6}$, y en los lugares desde los que se ejerce la crítica literaria. Los diversos autores coinciden desde mitad del siglo XIX en tres ideas principales a la hora de valorar la novela griega: la primera de ellas es, como no podría ser de otra manera, el juicio moral negativo que se hace sobre el género en general o sobre algunos de sus ejemplares en particular:

Heliodoro (...) compuso en su mocedad una novela (Ai $\imath \iota$ o $\iota \iota x \dot{\alpha})$ o sea los amores de Teágenes y Cariclea en 10 libros (...) Bástele para ocupar un lugar preferente la pureza de su moral, la dignidad y gracia del estilo y el no verse contaminada con el mal gusto de su tiempo ${ }^{7}$.

También debemos buscar en Grecia el origen de la novela (...) Dafnis y Cloe es una novela de pastores, que se atribuye a Longo, de quien no se tiene noticia alguna. Parece que sirvió de modelo al autor de Pablo y Virginia, quien aventajó mucho al griego por la mejor dirección de la intriga, y sobre todo por la mayor decencia ${ }^{8}$.

Tales son el Dafnis y Cloe, de Longo, lectura muy peligrosa para la juventud, que la excelente versión de Amyot al francés antiguo, ha propagado mas de lo que sería de desear9.

En muchas ocasiones, esta crítica moral va ligada al concepto de literatura de «decadencia» frente a la «auténtica» literatura griega, representada por la de época clásica:

Era la novela género literario desconocido de la antigua Grecia. $(\ldots)^{10}$.

La primera [razón] que á cualquiera se le alcanza (y esta explica igualmente por qué en todas las naciones modernas el género novelesco fue tan tardío relativamente á otros de amena literatura), es la escasez, ó mas bien dicho, la falta de modelos en que en este género nos dejó la antigüedad, gran maestra y fuente fecunda de nobles inspiraciones en todo linaje de artes de imitación. La antigüedad

${ }^{5}$ La última reimpresión de la versión de Mena es de 1787. Cf. TEIJEIRO FUENTES, Miguel Ángel. La Novela Bizantina en España. Cáceres: Ed. Universidad de Extremadura, 1988, p. 42.

${ }^{6}$ Un estudio en HUALDE PASCUAL, Pilar. «Panorama de los Manuales de Literatura Griega (1849-1868)». En: GARCÍA JURADO, Francisco, et.al. (eds.). La Historiografía de la Literatura Greco-Latina en el siglo XIX español: Espacio social y literario. Málaga: Analecta Malacitana, 2005, p. 109-134.

${ }^{7}$ GONZÁLEZ ANDRÉS, Raimundo. Breve Exposición Histórica de la Literatura Griega, dispuesta y ordenada para el uso de sus discípulos por Don..., Catedrático de Lengua y Literatura Griega en la Universidad de Granada. Madrid: Imprenta Nacional, 1855, p. 125.

${ }^{8}$ DÍAZ, Jacinto. Historia de la Literatura Griega, escrita por el Dr. D...., Pbro. Catedrático de Literatura Clásica en la Universidad de Sevilla. Barcelona: Imprenta del Diario de Barcelona, 1865, p. 374-375.

${ }^{9}$ OCHOA, Eugenio de (intr.). Tesoro de Novelistas Españoles Antiguos y Modernos. París: Baudry, 1847, p. iii.

${ }^{10}$ GONZÁLEZ ANDRÉS, Raimundo. Ibid., p. 125. 
clásica ninguna novela propiamente tal nos ha dejado (...) Las mas antiguas de que tenemos noticia, sobre estar muy distantes de poderse presentar como modelos, pertenecen ya á épocas de decadencia ${ }^{11}$.

La segunda idea señalada es la de las supuestas deficiencias estéticas de las novelas conservadas, frente al tímido y parcial elogio de alguna de ellas:

(...) Aquiles Tacio (...) escribió en ocho libros los amores de Clitofon y Leucipa. Adviértese poco arte en la disposición de la materia, identidad en los caracteres y tal prurito de descripciones que recarga pesadamente el estilo y entorpece el movimiento de la fábula. Sin embargo despierta interés, no carece de gracia y aun de verdad en sus situaciones, y su lenguaje recuerda la pureza ática. (...) Longo (...) dejó una novela pastoral Dafnis y Cloe en 4 libros. A vuelta de muchos defectos en el plan, en los caracteres y en el estilo agrada por cierta delicadeza, y por la naturalidad y concisión con que está escrita ${ }^{12}$.

La tercera idea supone que, aunque la novela pueda tener un remoto origen grecolatino, hay un completo divorcio entre aquélla y el género novelístico del momento, que es el único que se considera exponente de la perfección de la obra de arte:

De nuevo lo diremos: ipobres modelos en verdad! pero considérese también que no podía ser de otro modo. La novela es un género de literatura esencialmente moderno, si nos es lícito expresarnos así, un género que no hubiera podido desarrollarse y prosperar sin el auxilio de la imprenta ${ }^{13}$.

No las hemos de creer tan perfectas (si perfección ha en este género propia, fuera de la invención los caracteres y el estilo) como las de nuestros tiempos compuestas con tanto estudio y después de mil y mil maneras y modas; pero la invención es de los antiguos, es también de los griegos, y no nuestra ${ }^{14}$.

La primera reivindicación de la novela clásica sólo llegará al calor del debate estético que se establece entre los ilustrados del momento acerca del género novelístico, en el marco de un debate más amplio, en el que se polarizan las posturas idealistas de los partidarios del arte por el arte y las de los defensores del arte puesto al servicio de unos ideales, sea cual sea su signo. $\mathrm{Su}$ autor será el auténtico redescubridor y difusor de la novela griega en la España contemporánea: Juan Valera. Es destacable que su explícita reivindicación no se vaya a referir a la novela griega en general, sino al ejemplar hasta ese momento más denostado por su supuesta falta de moralidad, Dafnis y Cloe. La primera mención valerina de la obra de Longo se produce en 1860, en el contexto de su réplica al discurso de ingreso en la Academia Española del

${ }^{11}$ OCHOA, Eugenio de. Ibid.

12 GONZÁLEZ ANDRÉS, Raimundo. Ibid., p. 125.

${ }_{13}^{13}$ OCHOA, Eugenio de. Ibid., p. iii.

${ }^{14}$ FOZ, Braulio. Literatura Griega, esto es, su historia, sus escritores y juicio crítico de sus principales obras, por Don ..., catedrático de lengua griega en la Universidad Literaria de Zaragoza. Zaragoza: Imprenta y Librería de Vicente Andrés, 1849, pp. 117-118. 
escritor neoconservador Cándido Nocedal. Este pequeño ensayo de Valera, titulado «De la naturaleza y carácter de la novela», en el que el escritor defiende su postura idealista, termina, precisamente, con una alabanza para el autor de las Pastorales, en la que el egabrense resume toda su teoría estética:

Creo que la poesía, y por consiguiente la novela, se rebajan cuando se ponen por completo a servir a la ciencia; cuando se transforman en argumento para demostrar una tesis. Yo creo, por último, que si los autores de estas novelas doctrinales son legos, como sucede con frecuencia, o lo trastruecan y confunden todo, o nos enseñan cosas olvidadas ya de puro sabidas, redundando todo ello en muy notable menoscabo del esparcimiento, regocijo y deleite que de la lectura nos prometíamos. No condeno, sin embargo, que las doctrinas se divulguen por medio de las novelas. Si unas doctrinas son malas, otras son óptimas, y al cabo, en nuestro siglo, ni hay iniciación, ni misterios, ni enseñanza esotérica: todo se sabe por todos, mejor o peor, más temprano o más tarde. (....) No es esto conceder que la novela dogmática haya nacido en nuestra edad. Nihil novum sub sole. La novela dogmática es tan antigua como la novela misma. La Ciropedia es una novela política, y el cuento de Apuleyo, singularmente el hermoso episodio de los amores de Psiquis y Cupido, está lleno de símbolo, de las más profundas doctrinas platónicas.(...)Feliz el autor de Dafnis y Cloe, que no consagró su obrilla a Minerva, ni a Temis, sino a las ninfas y al Amor, y que logró hacerse agradable a todos los hombres, o descubriendo a los rudos los misterios de aquella dulce divinidad, o recordándolos deleitosamente a los ya iniciados. Ojalá viviésemos en época menos seria y sesuda que esta que alcanzamos se pudiesen escribir muchas cosas por el estilo ${ }^{15}$.

Todo ello ante un auditorio y en un contexto, el de la España de 1860, en que muy pocos eruditos conocían la lengua griega ${ }^{16}$ y en que, como anticipábamos, no existía versión de la novela de Longo a la lengua patria. Tan del gusto de Valera debió de ser esta obrita que 20 años más tarde, en 1880, la tradujo al español, tal vez sin sospechar la influencia que esto iba a tener no sólo en la literatura, sino en el mundo estético hispano de las siguientes décadas.

\section{LA TRADUCCIÓN DE JUAN VALERA. El PRÓlOGO: MORAL Y FILOLOGÍA. PlANTEAMIENTOS SOCIOLÓGICOS Y ESTÉTICOS}

La traducción de Valera aparece en España, pues, en 1880, cuando hacía ya más de un siglo que ninguno de los pocos helenistas con que contaba nuestro país se propusiera la traducción de un texto novelesco griego. Esta versión, además, cuenta con la circunstancia de que su autor reúne en sí dos

15 VALERA, Juan. «De la naturaleza y carácter de la novela». En: Estudios críticos sobre literatura, política y costumbres de nuestros días. Madrid: Librería de A. Durán, 1864, p. 254.

${ }^{16}$ Cf. HUALDE PASCUAL, Pilar, HERNÁNDEZ MUÑOZ, Felipe. «La Real Academia Greco-Latina y un documento inédito del siglo XIX en defensa de los estudios helénicos». Cuadernos de Filología Clásica: (egi) 2000, vol. 10, p. 283-286. 
condiciones: la de helenista y la de novelista. Efectivamente, el ilustrado egabrense, bien conocido como uno de los más importantes narradores españoles decimonónicos, es mucho menos conocido en su faceta de traductor. La formación de Valera en la lengua griega, fue, como se sabe, en buena medida autodidacta. Al ser aún muy deficientes los estudios de griego en la España en la que Valera pasa su primera juventud, nuestro autor emprenderá los estudios de este idioma a los 26 años, en Nápoles, de la mano de uno de sus amores platónicos, la marquesa de Bédmar, con la ayuda de un profesor griego. La posterior dedicación a su actividad como helenista es muy irregular. Sus proyectos de traducir a distintos autores griegos se multiplican, y probablemente hubiera alcanzado notables logros de no haber sido porque las ocupaciones mundanas y la reconocida pereza del andaluz le hicieron relegar indefinidamente sus proyectos de traducción de otros textos helénicos, como los de Hesíodo o Esquilo.

Muy diferente será la actitud que mantenga Valera con el texto de Dafnis y Cloe, que traducirá de un tirón en el otoño de 1879 , en un momento de personal felicidad y de retiro de su vida pública en su finca de Doña Mencía. En cualquier caso, las reducidas dimensiones de la obra de Longo y el tono pastoril y bucólico de la misma sintonizan mucho mejor con el carácter del escritor de Cabra que los largos textos mitológicos de Hesíodo o las solemnes tragedias de Esquilo ${ }^{17}$, amén de ser un referente estético, buen exponente de las ideas que el autor mantiene respecto a la obra artística ${ }^{18}$, como se veía en el discurso que pronunció ante la Academia Española antes mencionado.

En enero de 1880 sale a la luz la traducción del Dafnis y Cloe, para cuya primera edición Valera decide ocultar su nombre bajo el pseudónimo de Un aprendiz de helenista, de acuerdo con las convenciones habidas para los textos que pudieran tener problemas de carácter moral. La obra se vende bien ${ }^{19}$ y populariza la novelita de Longo en España.

La traducción de Valera iba precedida de un prólogo que ha sido traído a colación en diversas ocasiones, tanto por hispanistas ${ }^{20}$, como por helenistas $^{21}$.

${ }^{17}$ Cf. GARCÍA JURADO, Francisco; HUALDE PASCUAL, Pilar. Juan Valera (18241905). Madrid: Ediciones Clásicas, 1998, p. 35-56.

18 Para el mantenimiento del canon estético grecolatino, frente a las nuevas corrientes literarias debatidas en la época, cf. HUALDE PASCUAL, Pilar. «Jenofonte y Juan Valera: la voz del narrador de la historiografía griega a la novela española del siglo XIX». Exemplaria, 2001, vol. 5, p. 1-19.

${ }^{19}$ Cf. FERNÁNDEZ, Pura. «Juan Valera ante la polémica en torno a la moral en el arte: La traducción de Dafnis y Cloe o Las Pastorales de Longo (1880)». En: GALERA, Matilde (coord.). Actas del I Congreso Internacional sobre don Juan Valera. Córdoba: Diputación de Córdoba-Ayuntamiento de Cabra, 1997, p. 154.

${ }^{20}$ Cf. FERNÁNDEZ, Pura. Ibid. p. 149-158; SÁNCHEZ IMIZCOZ, Ruth. «Pepita Jiménez: Una novela griega a la española». Cuadernos de la Asociación de Licenciados y Doctores Españoles en Estados Unidos 1991, vol. VIII, n. ${ }^{\circ}$. I, esp. p. 55-60.

${ }^{21}$ GARCÍA JURADO, Francisco; HUALDE PASCUAL, Pilar. Ibid., p. 35-56. 
Este texto tiene un notable valor porque, junto con las notas finales de la traducción de Valera, puede dar cuenta de la complejidad de las ideas del autor tanto en posturas estéticas como morales en el entorno cultural del momento, además de ser una clara muestra del credo artístico valerino con respecto al género novelístico. Efectivamente, Valera vierte en este texto una serie de reflexiones personales centradas principalmente en esos dos aspectos, los estético-sociológicos y los morales, lo que proporciona también ciertas claves sobre la actitud del escritor con respecto al texto de Longo y sobre el público al que se dirige su traducción.

Las consideraciones estéticas se centran en el ya antiguo debate sobre los clásicos y los modernos ${ }^{22}$, en la condición de género de la modernidad que atribuye a la novela, y en la pertinencia de presentar la traducción al lector implícito de la obra.

La conclusión a la que llega Valera es que sólo los eruditos del momento son los receptores ideales de la literatura grecolatina, mientas que, aunque aún en este momento resulta prestigiosa la lectura de los clásicos para los «hombres de mundo», su interés por ella es pura apariencia, y contra estos elegantes se dirigirá especialmente la sátira de nuestro autor. Por otra parte, el gran público, en la terminología valerina «el vulgo», no presenta ni siquiera apariencia de interés por las literaturas de la Antigüedad.

Pese a este panorama poco propicio para dar a la imprenta el texto de Dafnis y Cloe, más aún cuando el traductor está especialmente interesado en que este trabajo sea un éxito editorial ${ }^{23}$, Valera argumenta su esperanza de triunfo en primer lugar, por el hecho de que se trate de un texto en prosa, más del gusto del público patrio que los clásicos en verso ${ }^{24}$, y, en segundo lugar, en que Dafnis y Cloe sea un texto novelesco, siendo, como es en el momento, la novela el género de moda. Esta reflexión le da pie para un largo excurso sobre el carácter y evolución de la novela en Occidente, en realidad, un

${ }^{22}$ No podemos por menos que evocar los ecos de la llamada Querelle, el debate estético que se extiende desde los círculos académicos franceses desde el siglo XVII acerca de la supremacía de los modernos sobre los clásicos, y su correspondiente contestación. Una visión de conjunto al respecto en FERNÁNDEZ GALIANO, Manuel. «Homero y la posteridad». En: Introducción a Homero. Madrid: Labor / Punto omega, 1984, pp. 139-145.

${ }^{23}$ Sobre su «esperanzas de gloria y de ganar algunos cuartos» que Valera confiesa por carta a Menéndez Pelayo, cf. FERNÁNDEZ, Pura. Ibid., p. 154.

${ }^{24}$ Los grandes clásicos en verso, en opinión de Valera, son rechazados por el público español, en primer lugar, por la existencia de una rica poesía patria que colma el ansia de deleite poético de los españoles, en segundo lugar, por el controvertido asunto de la difícil traslación del verso clásico al castellano. Para el debate de la traducción de los clásicos en prosa o en verso, cf. HUALDE PASCUAL, Pilar. «Valoración de las traducciones de Homero en los siglos XIX y XX en España e Iberoamérica: de Hermosilla a Leconte de Lisle». En: ÁLVAREZ MORÁN, Consuelo; IGLESIAS MONTIEL, Rosa María. Contemporaneidad de los Clásicos en el Umbral del Tercer Milenio. Murcia: Universidad de Murcia, 1999, pp. 169-177. 
pequeño ensayo sobre un tema que luego tocarán por extenso Emilia Pardo Bazán y Marcelino Menéndez Pelayo ${ }^{25}$. Al ser el género novelesco, a decir de Valera, el más sujeto a los vaivenes de la moda, estaría justificado que novelas muy populares en otras épocas, como la Diana de Montemayor, el Amadís y aun el excelso Quijote, hayan pasado a ser lectura exclusivamente de eruditos. Frente a esto, el gran público — nuevamente, «el vulgo»— tiene la percepción «muy sutil y despierta para comprender hasta los ápices y más menudos primores de Feuillet, Musset, Mérimée, Sue, Balzac, Dickens, Dumas, Victor Hugo y otra caterva de novelistas contemporáneos, extranjeros y aun españoles». Para el escritor cordobés, tanto ese «vulgo» como la «persona elegante y de mundo», que aburrida a las seis páginas de lectura de la Ilíada «acude, para desenojarse, a una novela de Daudet o de Belot, que le parece mil veces más agradable» tiene como único horizonte de expectativas la lectura de novelas contemporáneas, que le produzcan una agradable sensación de entretenimiento.

Frente a este desolador panorama respecto a la recepción de la literatura grecolatina, la esperanza de Valera es que su Dafnis y Cloe colme las expectativas de un público amplio, ya que, en su concepto estético, es una novela que presenta elementos de belleza absoluta y permanente en el tiempo, al margen de la volubilidad de las modas, lo que hará que todo tipo de público guste de ella.

Ciertamente, el autor reconoce que el hecho de la brevedad y sencillez del texto pueda contribuir a esta aceptación y aumenta la confianza del escritor en el triunfo editorial de la obra, a lo que contribuiría, asimismo, el que la versión valerina venga precedida de la gran polémica que en Francia se suscitó en 1810 al publicarse por primera vez su versión íntegra ${ }^{26}$. No obstante, presumimos que sea el suave erotismo de la obra del de Lesbos lo que avive la esperanza de Valera en el éxito comercial de la traducción.

En fin, quizá la más clara síntesis de la idea que ha llevado a Valera a publicar esta versión de Las Pastorales al castellano sea la que esgrime en el primer párrafo del texto «que esta novela es bonita e interesante, y que ha de gustar y divertir a los lectores», exponente del ideario de Valera sobre la necesidad de que el género novelístico esté desvinculado de compromisos sociales.

Asunto más controvertido han sido las reflexiones de orden moral que Valera incorpora en su prólogo ${ }^{27}$. El autor, convencido del posible escándalo

${ }^{25}$ En La Cuestión Palpitante, 1883, y Los Orígenes de la Novela, 1909, respectivamente.

${ }^{26}$ Los avatares del hallazgo del manuscrito con el texto completo de Longo por parte de Paul Louis Courier en una abadía de Florencia y su polémica con su oponente, Furia, que pretendía hacerse con la gloria de la edición del texto quedó reflejada en sus cartas al editor, que en español fueron publicadas con el título de Historia de una Mancha de Tinta, (el manuscrito de Longo). Valencia: Castalia, 1948.

${ }^{27}$ Para el tema de la moral en la obra de Valera, a partir de las ideas expuestas en el prólogo de su traducción de Longo, cf. FERNÁNDEZ, Pura. Ibid., pp. 149-158. 
que pueda provocar la publicación de la obra — con esta clave hemos de entender que en su primera edición figure el traductor bajo pseudónimo-, se adelanta a los posibles comentarios adversos, en defensa de la moralidad del texto. Para esto se sirve de dos conceptos, el de lo licencioso y el de lo perverso. Lo licencioso, aquello que, vedado a las convenciones del momento, pone de manifiesto el extremo realismo del texto de Longo, es admitido por nuestro autor (por cierto, muy tolerante en cuestiones de esta índole). En este punto se desarrolla un tema que tendrá gran trascendencia en el siglo XIX: el del desnudo. En el ideario de Valera, desnudo no es sinónimo de inmoralidad, sino de ingenuidad natural e inocente. Frente al candor de Cloe, Valera opone la deshonestidad de ciertas heroínas novelescas del momento (la Fanny de Ernest Feydau, la Emma Bovary de Flaubert, la Margarita Gautier de Alejandro Dumas) y aún la Margarita del ya clásico Fausto, movidas por intereses mundanos ajenos al amor, pero aceptadas socialmente porque su impudor aparece recubierto con ropajes.

Distinto es el concepto que Valera califica de perversión. Valera confiesa sentirse autorizado para «cambiar o suprimir» lo que pudiera haber de perverso en el texto de Longo, en lo que, como vemos, no se aparta mucho de las líneas de la censura de la novela griega empleadas en España, desde el siglo XVI. Esta perversión se restringe, no obstante, a la homosexualidad presente en la novela en el episodio de Gnatón, que Valera consigue obviar haciendo a Cloe objeto del deseo del parásito, en lugar de Dafnis, tal y como aparece en el texto griego. Se modifica, por tanto, parte del contenido de la novela. En este sentido, cuenta ya Valera con un ilustre precedente en la traducción de novela griega al español: la versión de Leucipa y Clitofonte de Diego de Agreda y Vargas (1617), quien había utilizado un procedimiento similar para obviar un episodio de homosexualidad sustituyendo al efebo por la amada Teófila $^{28}$. No obstante, también en otros pasajes nuestro traductor se esfuerza en suavizar los términos, como en la explícita escena del acto sexual entre Dafnis y Licenion, aunque de eso no se nos habla en el prólogo, que está escrito en términos más populares, sino en las eruditas notas finales que aparecen, al menos, en la primera edición.

De la lectura atenta de los textos marginales de la traducción de Longo que realizó Valera podemos extraer diversas conclusiones, que serán de interés para perfilar la relación del autor cordobés con los clásicos antiguos: El autor, según propia confesión epistolar a su amigo Menéndez Pelayo ${ }^{29}$, «grecolatino y clasicote hasta los tuétanos», prefiere los clásicos grecolatinos a los modernos, una rareza en el mundo literario del momento. Curiosamente, la novela — género que le ha dado la celebridad— es considerada por nuestro

\footnotetext{
${ }^{28}$ Cf. CRUZ CASADO, Antonio. Ibid., p. 287.

${ }^{29}$ En carta a Menéndez Pelayo del 8 de julio de 1878, un año antes de emprender la traducción de la novela de Longo.
} 
autor como un género menor, $y$, en términos generales, la novela moderna (en la que incluye a autores románticos como Víctor Hugo, Sue, Merimée, Musset o Dickens, autores de folletín como Dumas o Adolphe Belot, e incluso algún autor de los inicios del realismo, como Balzac o, en parte, Feuillet y Daudet) es considerada como un mero entretenimiento para las masas, juicio que es exponente de su postura idealista que defiende «el arte por el arte ${ }^{30}$ frente a la llamada novela de tesis. Pese a que su intención con la traducción de Dafnis y Cloe es aparentemente divulgativa, según los estudiosos de la vida y obra de nuestro autor, parece ser que también implicaba una intención crematística, que se vio sobradamente cumplida ${ }^{31}$. No obstante, las muy eruditas notas finales, así como la alusión al escándalo habido en Francia por el asunto de la «mancha de tinta» del editor del texto Courier, cuestión muy concreta que afectaba tan sólo a un círculo de ilustrados, hace pensar que, en buena medida, Valera quiso que su obra se difundiese y estimase en los círculos eruditos del momento, entre los escasos helenistas con que contaba la España de la época. Respecto a la censura, también Valera adopta una postura ambigua, pues respeta las trabas morales impuestas a este tipo de literatura, pese al relativo atrevimiento de traducir una obra de estas características.

Lejos estaba el autor cordobés en este momento de calcular la impronta estética que su traducción tendría en los círculos literarios y artísticos de los años subsiguientes.

\section{REACCIONES A LA TRADUCCIÓN DE VALERA. OPINIONES CONTRAPUESTAS. SU IMPRONTA EN LA LITERATURA Y EN EL ARTE}

Las reacciones a la publicación del Dafnis y Cloe pronto se hicieron notar en el ámbito cultural de la época. La popularidad de la traducción de Valera excedió con mucho de los círculos filológicos del momento y, desde luego, se tienen más noticias del eco popular que tuvo en la prensa y de las valoraciones que de ella hicieron diversos literatos que de las reacciones que pudo haber suscitado entre los profesores de lenguas clásicas. Sin embargo, el rechazo mayoritario no vino de la burguesía bienpensante, ni de las autoridades civiles, algo que el escritor había tratado cuidadosamente de evitar con sus «arreglos» e, incluso, con el empleo de pseudónimo. Así lo atestigua la reseña publicada apenas un mes después de que la traducción saliera de la imprenta, en febrero de 1880, y firmada con las iniciales Ch.H. en el Boletín

\footnotetext{
${ }^{30}$ Un análisis detallado de las posturas estéticas de Valera al respecto en OLEZA, Joan. «Don Juan Valera: Entre el diálogo filosófico y el cuento maravilloso». En CUEVAS, Cristóbal (ed.). Juan Valera. Creación y crítica. Málaga: Publicaciones del Congreso de Literatura Española Contemporánea, 1995, p. 111-146.

31 Cf. FERNÁNDEZ, Pura. Ibid., p. 154.
} 
Bibliográfico de la Revista Contemporánea. Allí se afirma que la prensa ha filtrado desde el primer momento el nombre del traductor, cuyo estilo se alaba sin ambages, aunque no se deja de sugerir con benevolencia la posible falta de comprensión por parte de los lectores de la clase de obra que se les ofrece a la vez que se manifiesta la sospecha de que sólo las personas «más ilustradas y apegadas a los estudios clásicos comprenderán todas las bellezas que encierran Las Pastorales de Longo» considerando que «hay escenas más que picantes, muy del gusto, ciertamente de las literaturas griega y latina, pero que en la época actual no son miradas con buenos ojos» ${ }^{32}$.

En contraposición a esta opinión moderada, las mayores críticas vinieron por el lado periodístico y por parte de los representantes del Naturalismo más descarnado. Éstos, afectados duramente por la censura gubernativa, veían que el erótico texto de Valera se había «aligerado» lo suficiente como para pasar sin trabas todos los controles. En este sentido, fue notable la polémica que se suscitó entre Valera y López Bago ${ }^{33}$ —estudiada en detalle por Pura Fernández-, cuando, encausado este último por la publicación de La prostituta, su abogado defensor alegó la diferencia de trato que suponía la libertad de difusión de la traducción de Longo escrita «por el sensualismo y para el sensualismo», lo que, en definitiva, contribuyó a conseguir la absolución de escritor por el Tribunal Supremo.

Las reacciones de los más radicales llegaron a traspasar las fronteras, como se puede ver en la crítica del escritor peruano, de corte realista y tendencias anarquistas, Manuel González Prada, quien en su obra Pájinas Libres (1894) critica la autocensura de la traducción de Valera en el pasaje homosexual de Gnatón, ya que «no sólo transforma en mujer a un hombre, sino hace y deshace del Libro IV como si fuera obra de su propiedad», y llega al punto de añadir este cruel comentario respecto a la supuesta doble moral del autor.

¿Será Valera como algunos spinsters o solteronas inglesas que a solas se pasan horas enteras con los ojos fijos en un estereoscopio de fotografías pornográficas, mientras en público se sonrojan i miran al cielo cuando escuchan hablar de brazos i pantorrillas? $?^{34}$.

Frente a tan duras opiniones, hay un grupo de intelectuales españoles que apreciaron, sin ningún género de dudas, la traducción de Valera, desde su amigo Clarín — quien, no obstante, desaconseja púdicamente su lectura a las

${ }^{32}$ Revista Contemporánea, 15 de febrero de 1880, t. XXV, p. 344.

${ }^{33}$ La postura opuesta al Naturalismo que representa la novela de López Bago aparece en repetidas ocasiones en la correspondencia entre Valera y Narciso Campillo, desde Noviembre de 1884 a Diciembre de 1885, con ocasión de la polémica suscitada por la publicación de La Prostituta, y en noviembre de 1885 reconoce el autor de Pepita Jiménez la mala opinión que de él tiene López Bago (cf. Juan Valera. Correspondencia. ROMERO TOBAR, Leonardo (ed.). Madrid: Castalia, 2005, vol. IV, p. 408).

${ }^{34}$ GONZÁlEZ PRADA, Manuel. Pájinas Libres. Paris: Paul Dupont, 1894, 297 p. 
damas $^{35}$ — hasta Armando Palacio Valdés, quien en carta a Clarín del 19 de julio de 1891 asegura que «Su traducción de Dafnis y Cloe, de Longo, es una maravilla. Dudo que en el original griego resulte más deliciosa esta novela ${ }^{36}$, pasando, desde luego, por doña Emilia Pardo Bazán, de ideales estéticos tan opuestos a los de Valera, si bien reconoce los valores y la graciosa elegancia de la novela de Longo en el ensayo donde plantea el debate naturalista en España, La cuestión palpitante (1883):

Me represento a Dafnis y Cloe como un bajo-relieve pagano cincelado, no en puro mármol, sino en alabastro finísimo. Sobre el fondo de una rústica cueva, donde se alza el ara de las ninfas rodeada de flores, retozan el zagal y la zagala adolescentes, y a su lado brinca una cabra y yace caído el zurrón, el cayado, los odres llenos de leche fresca; el diseño es elegante, sin vigor ni severidad, pero no sin cierta gracia y refinada molicie que blandamente recrean la vista ${ }^{37}$.

Y, pasado el tiempo, y vueltas las aguas a sus cauces, la traducción de Valera tuvo la peculiaridad de ser motivo de elogio en el que fuera el último artículo periodístico de doña Emilia, publicado de forma póstuma. En él la escritora gallega nos glosa la figura de Valera y se refiere, en concreto, al hecho de que la primera obra que ella leyó del andaluz fuera su traducción del Dafnis y Cloe, que, por cierto, afirma preferir a la clásica de Amyot, hecho en el que, al parecer, han pesado los púdicos «arreglos» de Valera, frente a la «crudeza de original» que presenta el obispo francés:

Lo primero que yo leí de Don Juan [Valera] fue una traducción directa del griego, «por un aprendiz de helenista» rezaba modestamente la portada. Me pareció una égloga encantadora adaptada por un enamorado de la antigüedad eternamente joven: un idilio de la Antología, extendido a la novela ${ }^{38}$. Lo preferí al de Amyot, que no perdona la crudeza del original ${ }^{39}$.

Pero, al margen de la admiración explícita por la versión, fueron muchos los autores españoles del momento, de muy distintas tendencias, en los que se deja notar la influencia de Valera, bien en la inventio de los temas y planteamiento de las tramas, bien en la mención explícita de la obra o de alguno de sus textos o personajes en rico juego de intertextualidades: dentro de un extremo del arco ideológico en el que se situaron los autores de la llamada generación del 68, hemos de mencionar al asturiano Palacio Valdés. Este,

${ }^{35}$ Cf. CLARÍN, Leopoldo Alas. Obra Olvidada: Artículos de Crítica [por] Clarín. RAMOS-GASCÓN, Antonio (sel. e intr.). Madrid: Ediciones Júcar, 1973, p. 152.

${ }^{36}$ Epistolario a Clarín. (Marcelino Menéndez y Pelayo, Leopoldo Alas, Miguel de Unamuno, Adolfo Alas, Armando Palacio Valdés). Madrid: Ediciones Escorial, 1941, p.118.

${ }^{37}$ PARDO BAZÁN, Emilia. La Cuestión Palpitante, edición de. José Manuel González Herrán. Barcelona: Anthropos Editorial, 1989, p. 188.

${ }^{38}$ Se refiere con toda probabilidad a los elementos de la bucólica presentes en la obra de Longo.

${ }^{39}$ PARDO BAZÁN, Emilia. «Un aprendiz de helenista». ABC, 13 de mayo de 1921. 
además de expresar su admiración por la obra de Longo traducida por Valera en carta a su paisano Leopoldo Alas, propone el Dafnis y Cloe como canon dentro del género novelístico desde diversos lugares de su obra y a lo largo de toda su vida literaria ${ }^{40}$. Así sucede desde la introducción de una de sus primeras novelas, Los Majos de Cádiz (1896), en la que afirma: «Nada hay comparable á la célebre novela de Longo Dafnis y Cloe. En ella pueden verse reunidas todas las perfecciones del género (...)» ${ }^{41}$, hasta su obra póstuma Album de un viejo (1940), donde dice: «Hace también muchos años escribía en Grecia, Longo su famosa novela Dafnis y Cloe, que puede ser modelo eterno del género» ${ }^{42}$, amén de introducir muy pronto en sus obras de corte naturalista - al margen de su marcado conservadurismo- las menciones de Dafnis y Cloe, como en Años de juventud del doctor Angélico $(1918)^{43}$, y de haber constituido alguna de sus novelas con claros ecos de la novela de Longo, caso de La Aldea perdida (1903) ${ }^{44}$. No deja de ser reseñable la admiración que un autor tan conservador en sus ideas morales sintiera por la obra de Longo. Cabe decir que a ello contribuyó, seguramente, el hecho de que en la ficción del texto griego los protagonistas sólo consumaran su amor después de la celebración del matrimonio. Eso podría ser compatible con el ideario de un escritor que concebía, no ya la unión libre, sino el propio matrimonio civil como degradación para la mujer y comparable al apareamiento de los perros en la calle ${ }^{45}$, aunque, como admirador sin límites de los clásicos grecolatinos, disculpe la desnudez en sus obras con argumentos similares a los ya aducidos por Valera en el prólogo a su traducción de las Pastorales:

¡La Grecia! ¡Siempre la Grecia! ¡Cuán superficialmente juzgamos a este pueblo escogido de la Humanidad! Vemos sus estatuas desnudas y decimos: «Los escultores griegos no conocían la moral.» Como si la moral dependiese exclusivamente en la tierra de un pedazo más o menos grande de tela... ${ }^{46}$.

${ }^{40}$ Cf. PASCUAL RODRÍGUEZ, Manuel. Armando Palacio Valdés. Teoría y Práctica Novelística. Madrid: SGEL, 1976, p. 23-24, 51.

${ }^{41}$ PALACIO VALDÉS, Armando. Los Majos de Cádiz. Madrid: Tipografía de los hijos de M. G. Hernández, 1896, p. XXXIV.

${ }^{42}$ PALACIO VALDÉS, Armando. Album de un Viejo: Segunda parte de la «Novela de un Novelista». Madrid: Librería general de V. Suárez, 1940, p. 15.

${ }^{43}$ «...compraré algunos bueyes, aprenderé a tocar la flauta y representaremos aquí una vez más el idilio de Dafnis y Cloe.»

${ }^{44} \mathrm{La}$ identificación es antigua, cf. PESEUX-RICHARD. Henri. «Armando Palacio Valdés». Revue Hispanique, 1918, vol. XLII, p. 5- 80.

${ }^{45}$ Resulta estremecedor leer con ojos actuales la descripción que hace, en Album de un Viejo, de la salida del Juzgado de una recién casada cuya mirada se califica de «fugitiva, glacial, que aspiraba a ser indiferente, pero donde se leía la vergüenza» frente a la desposada por el rito religiosos que «paseaba una alegría triunfal». Su alegato en favor de la familia y de la posición más tradicional de la mujer en el hogar termina con estas palabras: «Si os interesa la dignidad de vuestro hogar, dejad que suba al altar la joven desposada». Corría el año 1929.

${ }^{46}$ PALACIO VALDÉS, Armando. Discurso de ingreso en la Real Academia Española, 1920. 
Más notable es, sin duda, el uso que el Naturalismo, tan denostado por Valera, hizo de la novelita del autor griego. Desde luego, resulta insuperable que la obra considerada como uno de los mayores exponentes de esta corriente en España sea, precisamente, aun sin nombrar Las Pastorales, una versión de la novela de Longo, trasladada a la Galicia rural y que, sobre el tema amablemente erótico del de Lesbos, se elabore una trama en la que el determinismo conduzca al incesto y a un final trágico, tan diferente del que corona la novela de los amantes de la isla griega. Esta magistral «vuelta de tuerca» la debemos a la Condesa de Pardo Bazán, quien en La Madre Naturaleza (1887) sabe aunar su admiración por el tema de la iniciación sexual en un ambiente bucólico con el credo naturalista que profesa ${ }^{47}$.

Pero, desde luego, es particularmente destacable, dentro del Naturalismo radical español la obra titulada El cura. Caso de incesto. Novela médico-social (1884) del propio López Bago, ya mencionado como acérrimo enemigo estético e ideológico de Valera. En esta obra, integrada dentro de la novela «feísta», que se goza en resaltar las patologías pseudomédicas, no sólo se menciona explícitamente Dafnis y Cloe, sino que se introduce, cerca del final de la obra, un pasaje entero de la traducción valerina. Se trata del episodio de la fiesta de bodas campestre de los pastores lesbios, que terminará con la consumación del himeneo de los nuevos esposos, y que sirve de comparación dentro del episodio donde se describe la boda de unos paisanos, a la que asiste el cura protagonista que poco después cederá al incesto. La cita aparece en estos términos:

La boda fue tal, que podría describirse casi con la misma pluma de Longo: «Viendo Dionisófanes que el tiempo era excelente (....) y Cloe conoció por primera vez que todo o hecho antes entre las matas y en la gruta no eran más que simplicidad o niñería ${ }^{48}$.

Este intertexto, en opinión de Pura Fernández, responde a un intento de demostrar el carácter sensual del pasaje de Longo, ya que el recuerdo del ambiente de la boda, no la de Dafnis y Cloe, sino la de los paisanos con la que se compara, crea una atmósfera erotizada entre los dos hermanos que precipita el incestuoso desenlace ${ }^{49}$. Sin embargo, no en todos los autores tiene un sentido tan combativo la mención explícita de la obra de Longo y de sus personajes, sino que otros escritores de corte realista (algunos de ellos, por cierto, con rasgos que son precedentes de la novela erótica) se refieren a los

${ }^{47}$ Cf. HUALDE PASCUAL, Pilar. «La pervivencia de la novela griega en Emilia Pardo Bazán: Dafnis y Cloe y Madre Naturaleza». En: ENCINAR, Ángeles; LÖFQUIST, Eva; VALCÁRCEL, Carmen; (eds). Género y Géneros: Escritura y Escritoras Iberoamericanas. Madrid: UAM, 2006, p. 159-172.

${ }^{48}$ LÓPEZ BAGO, Eduardo. El Cura: Caso de Incesto: Novela Médico-Social. FERRERAS, Ignacio (ed.). Madrid: Vosa, 1996, p. 214.

${ }^{49}$ Cf. FERNÁNDEZ, Pura. Ibid., p. 156. 
personajes de Longo, bien como mero recurso comparativo, en paralelo a la utilización de personajes mitológicos varios, o como mero recurso estético. Es el caso de Jacinto Octavio Picón, que en tres de sus obras hace mención de los personajes del novelista griego en contextos «galantes». En la primera y más famosa de sus novelas, Dulce y sabrosa (1891) se reconocen en la protagonista una serie de virtudes, comparándola con personajes femeninos del mundo clásico y al personaje de Cloe se atribuye la condición de enamorada:

Un clásico hubiese dicho de ella que era hermosa como Diana, amante como Alceste, compasiva como Antígona y, sobre todo, enamorada como Cloe ${ }^{50}$.

y el seductor coprotagonista compara a su querida con una obra literaria sólo por él leída y gustada, ante la sospecha que los próximos amantes de la joven no serán capaces de comprenderla en los mismos términos:

Quien leyese luego todo aquello, ¿sería capaz de apreciarlo? Acaso el tomo cayera en manos de un hombre zafio y rudo. ¡ Vaya usted a saber si un escribano, un comerciante, un militarote, tendrán sensibilidad para aprecia la candorosa impaciencia de Cloe en Las Pastorales, de Longo, o la exquisita voluptuosidad que hace palpitar el corazón de la Sulamita en el divino Cantar de los Cantares! ${ }^{51}$.

Asimismo, en Juanita Tenorio (1910), Picón menciona el personaje femenino de la novela griega, por boca de la propia protagonista-narradora, quien compara su belleza de juventud con la de Manon Lescaut y la de Cloe, tal vez sugiriendo, al asociar estos dos personajes, que ambas obras, la de Longo y la del abate Prévost, comparten el mismo carácter de novela «galante».

Porque en mi figura se daban juntas la apicarada monería de la francesita que trastornó al caballero des Grieux y la clásica pureza de formas de la chiquilla griega que despertó el amor de Dafnis ${ }^{52}$.

Todavía utilizará Picón una vez más, dentro un relato breve titulado El ideal de Tarsila (1888), en el que la lectura de la obra de Lesbos aparece inserta en un contexto erótico: Tarsila, mediante una estratagema, roba el amante a su prima, prototipo de la mujer sensual y apasionada para la que Dafnis y Cloe es lectura favorita. Al final del relato, será la propia Tarsila la que retome la lectura del libro con su amante, lectura interrumpida sistemáticamente por las necesidades imperiosas de la pasión:

De noche iba Carlos a verla. Sabiendo lo mucho que le gustaba Dafnis y Cloe, le esperaba ella con el libro sobre la mesa del gabinete. Pero leían poco; porque él

${ }^{50}$ PICÓN, Jacinto Octavio. Dulce y sabrosa. SOBEJANO, Gonzalo (ed.). Madrid: Cátedra, 1976, p. 144.

${ }^{51}$ PICÓN, Jacinto Octavio. Dulce y sabrosa. SOBEJANO, Gonzalo (ed.). Madrid: Cátedra, 1976, p. 172-173.

${ }^{52}$ PICÓN, Jacinto Octavio. Juanita Tenorio. Madrid: Librería General de Victoriano Suárez, 1910, p. 27. 
había discurrido un juego más bonito que la novela. Sentados ambos en la misma butaca, Tarsila iba leyendo lentamente, y por cada vocal que pronunciaba le daba él un beso... ${ }^{53}$.

Otro autor coetáneo que hace un uso interesante de las menciones de la obra de Longo, es José Ortega y Munilla. Escritor y periodista, uno de los más jóvenes y precoces de esta generación, se debatió, en principio, entre las corrientes naturalista y realista, y se encauzó finalmente por esta última siguiendo los pasos de su admirado Galdós. No obstante, es destacable para el asunto que nos ocupa el que su despertar a la literatura lo hiciera de mano de don Juan Valera, por obra y gracia de la lectura de su Pepita Jiménez, según el mismo confiesa en el prólogo de sus Relaciones Contemporáneas (1879-1884):

... no hubiera escrito nunca, si no hubiera aparecido en los escaparates de Durán, la vieja librería de la Carrera de San Jerónimo, una novela que se titula Pepita Jiménez ${ }^{54}$.

Desde luego, tal vez esta confesión puede explicar las numerosas alusiones a los personajes de la novela griega traducida por el egabrense, aun desde sus primeras obras. Estas referencias se producen en sentido muy variado: es notable el uso que hace de la mención de la pareja de pastores lesbios en un relato breve de carácter alegórico, titulado «Fábula Naturalista» ${ }^{55}$, en el contexto de una alabanza de la poesía bucólica representada por Teócrito, dentro del debate estético entre la poesía neoclásica del XVIII, el Romanticismo, los clásicos griegos y, cómo no, el género a debate en el momento, el Naturalismo. Pero, de entre todas las alusiones que de la obra del novelista Lesbos hace Ortega en su narrativa, llama la atención la que aparece en su novela Cleopatra Pérez al describir los pasos alegres y desinhibidos de dos hermanas huérfanas sevillanas una de las cuales acabará siendo prostituta de altos vuelos- y que nos vuelve a recordar las propias advertencias del Valera traductor del texto, o de las primeras críticas periodísticas a su traducción, que afirmaban que sólo podrían gustar de este texto novelesco y no escandalizarse las personas «versadas en letras griegas», expresión retomada ahora por el autor de Cleopatra Pérez con una intención claramente cómica o paródica:

... las escenas idílicas de la casa de las dos ventanas resucitaron los buenos tiempos del Longo; y como el alcalde de barrio no estaba versado en letras griegas, impuso a las niñas unas correcciones disciplinarias muy enérgicas, que las desacreditaron completamente en el barrio y les obligaron a tomar el camino de Madrid ${ }^{56}$.

${ }^{53}$ PICÓN; Jacinto Octavio. El Ideal de Tarsila. En: Mujeres, Obras Completas. Madrid: Renacimiento, s.f., vol. 4, p. 286.

${ }^{54}$ ORTEGA MUNILLA, José. Relaciones Contemporáneas: Novelas Breves. Madrid: Calpe, 1919, p. 7.

${ }_{55}$ Incluido en la obra Orgía de Hambre. Madrid: El Cosmos editorial, 1884.

${ }^{56}$ ORTEGA MUNILLA, José. Cleopatra Pérez. FERRERAS, Ignacio (ed.). Madrid: Cátedra, 1982, p. 52-53. 
Sin embargo, si hay un uso reseñable del tema de Longo en Ortega y Munilla es su empleo en distintas ocasiones de la mención de Dafnis y Cloe en el contexto de una ékfrasis, es decir, en una descripción de obras de arte, siguiendo, sin ningún género de duda, el camino iniciado por Valera en 1874, al final de su Pepita Jiménez, en el párrafo en que describe el pabellón de campo de los felices esposos:

En la casa de mis hijos hay, pues, algunas salas que parecen preciosas capillitas católicas o devotos oratorios; pero he de confesar que tienen ambos también su poquito de paganismo, como poesía rústica amoroso-pastoril, la cual ha ido a refugiarse extramuros.[...] El merendero o cenador, donde comimos las fresas aquella tarde, que fue la segunda vez que Pepita y Luis se vieron y se hablaron, se ha transformado en un airoso templete, con pórtico y columnas de mármol blanco. Dentro hay una espaciosa sala con muy cómodos muebles. Dos bellas pinturas la adornan (...), otra representa a Cloe cuando la cigarra fugitiva se le mete en el pecho, donde, creyéndose segura, y a tan grata sombra, se pone a cantar, mientras que Dafnis procura sacarla de alli ${ }^{57}$.

Algo similar hace Ortega y Munilla en la descripción de ciertas obras que decoran una mansión descrita en su primera obra, La cigarra (1879), y en donde se señala la marcada división entre imaginería cristiana y pagana de forma paralela a la vista en Valera:

Butacas, sillas, veladores de caoba, de seda, de palosanto: cuadros en que se notaba la respetable pátina de la antigüedad, y que eran ya de asunto sagrado degollación de san Juan, la toma de Jericó, la cabeza de Holofernes- ya de inspiración profanísima —un grupo de Napeas jugando al corro con alegre compañía de faunos, unos y otras en cueros, como su madre olímpica los parió, Dafnis y Cloe; Flora y Céfiro abrazándose... ${ }^{58}$.

Este texto, que salió a la luz meses antes de la traducción del Dafnis y Cloe de Valera, tiene como única fuente (hasta el punto de que resulta una mera copia del hallazgo valerino) su Pepita Jiménez. Pero el autor innovará años después el mismo motivo en la descripción de unos objetos de orfebrería que Cleopatra Pérez se apresura a recoger de la lujosa casa de la que va a ser desahuciada: se trata de una pareja de candelabros, uno de los cuales representa a la pareja de amantes lesbios y el otro, curiosamente, a sus continuadores en la literatura francesa, Pablo y Virginia, protagonistas de la obra homónima de Bernardino de Saint Pierre, a los que el mismo Valera, dentro de su prólogo de la traducción de Longo, había señalado como consecuencia

57 VALERA, Juan. Pepita Jiménez. ROMERO TOBAR, Leonardo (ed.). Madrid: Cátedra, 1989, p. 393.

${ }^{58}$ ORTEGA MUNILLA, José. La Cigarra. Relación Contemporánea. Sevilla: Fco. Álvarez y Cia., 1882, p. 68. 
de la influencia de la novela del de Lesbos ${ }^{59}$. Desde luego, aquí Ortega Munilla hace, asimismo, un guiño a su admirado Valera.

Si estaba en el salón el triunvirato de la ley haciendo inventario de los muebles, ella se fue al gabinete, y en un saquito de mano que traía Irene iba escondiendo lo que sobre las mesas había de algún valor: un par de candelabros que representaban una escena idílica: Pablo y Virginia bajo la palmera; Dafnis y Cloe bajo el risco $^{60}$.

Hemos de decir, no obstante, que lo que en principio parece un motivo literario del momento pasa de alguna manera a ser una realidad, ya que está constatado cómo en la pintura del momento se pone de moda, en paralelo a lo sucedido en la literatura, el tema de Dafnis y Cloe. Son bastantes, en efecto, los pintores que por estos años llevan a cabo alguna pintura desarrollando el bucólico tema de los pastorcillos lesbios ${ }^{61}$, caso del alcarreño Alejo Vera, del mallorquín Francisco Maura, del vasco José Echena o del tal vez más conocido de ellos, Gonzalo Bilbao, quien con un cuadro sobre el tema de la novela de Longo ganó la segunda medalla en el Concurso Nacional de Bellas Artes en $1887^{62}$ y consiguió un gran éxito de popularidad.

\section{LA TRAdUCCión de COlOMbine PARA la editorial Prometeo. ¿Litera- TURA CLÁSICA Y LITERATURA ERÓTICA?}

Es evidente, pues, que no sólo el éxito editorial, sino también el prestigio literario acompañaron a la traducción de Valera durante los últimos años del XIX y primeros del XX, hasta el punto de crear una cierta moda en los gustos estéticos, no sólo literarios, sino también en los imperantes en otros ámbitos de las Bellas Artes. Ello justifica que dicha traducción conociera sucesivas ediciones. Sin embargo, no hay propuesta de una nueva traducción del texto de Longo al español hasta la que nos llega de la mano de Carmen de Burgos, en 1910. La situación cultural española respecto a los estudios clásicos ha cambiado sustancialmente en este momento con respecto a aquel 1880 en que Valera diera a luz su traducción de Dafnis y Cloe. Ahora, instaurados ya los

${ }^{59}$ Un análisis actual en GARCÍA GUAL, Carlos. «Dos idilios novelescos, de Dafnis y Cloe a Pablo y Virginia». Revista de Occidente 1997, vol. 197, p. 99-115

${ }^{60}$ ORTEGA MUNILLA, José. Cleopatra Pérez. FERRERAS, Juan Ignacio (ed.). Madrid: Cátedra, 1982, p.183.

${ }^{61}$ Sobre el tema clásico en la pintura del momento, y sobre el motivo concreto de la novela de Longo Fabrés y su Tiempo, 1854-1938. México: Museo Nacional de San Carlos, 1994, p. 25.

${ }^{62}$ Sobre la adecuación de la pintura de Bilbao a la novela griega que le da nombre y tan de moda sólo siete años después de la traducción de Valera, puede verse la reseña aparecida en el n. ${ }^{\circ} 22$ de la Ilustración Española y Americana, diciembre de 1887, p. 382. 
estudios helénicos en la Universidad española, se comienzan a ver los frutos de algunas traducciones académicas, llevadas a cabo ya no por aficionados, sino por profesores de lenguas clásicas. Sin embargo, como alternativa a esta difusión científica de los textos de los clásicos, surge una editorial en la que se vierten al español las grandes obras de la Literatura Universal y que, en el caso de los griegos y latinos, nunca se hace desde el original, sino por medio de traducciones indirectas desde del francés: se trata de la editorial Prometeo, dirigida por el escritor Blasco Ibáñez. Concebido este proyecto editorial, según ya indica el nombre del titán portador del fuego, como una acción trasgresora que pretende arrebatar la cultura del reducido círculo de los privilegiados y acercarla al pueblo, dentro de su producción se comprenden obras literarias de muy distinto signo, habitualmente comprendidas en la colección Obras maestras de la Literatura Universal ${ }^{63}$.

No será este el caso de la novela de Longo, que se publica en colección aparte, bajo el epígrafe de Los clásicos del amor, donde comparte protagonismo con El Asno de Oro de Apuleyo o los Epigramas Eróticos de Marcial, entre los antiguos, junto a otras obras modernas de corte erótico, como Las Canciones de Bilitis de Pierre Loüys o Vida de las Casadas y las Cortesanas de Pietro Aretino. Concebida, pues, de alguna manera, como obra de la llamada en el momento «literatura galante» ${ }^{64}$, la encargada de su traducción, en este caso, será la almeriense Carmen de Burgos Seguí, más conocida por el pseudónimo de Colombine. Carmen fue una mujer polifacética, periodista, escritora, traductora, profesora de la escuela normal, asidua en los círculos de la intelectualidad española de los años diez y veinte en nuestro país. Defensora de los derechos de la mujer y con grandes inquietudes sociales, es en este contexto donde en torno al año 1904 se fragua su amistad con Blasco Ibáñez ${ }^{65}$, con quien comparte ideales estéticos y sociales, momento a partir del cual colabora ocasionalmente en su editorial. Colombine por estos años se ha dedicado con afán a labores de traducción de clásicos modernos tan diversos como Leopardi, Moebius, Tolstoi, Renan, Nerval, Ruskin o Salgari, pero es esta la primera y única ocasión en que pretende hacer la versión de un clásico antiguo. Es preciso, pues, preguntarnos cuál fue la relación de esta intelectual con el mundo grecolatino. Desde luego, su formación autodidacta, hecha a partir de las más diversas lecturas en la biblioteca paterna, no le po-

${ }^{63} \mathrm{Cf}$. «Aproximación al catálogo de la editorial Prometeo». En: Vicente Blasco Ibáñez: y el Periodismo se hizo Combativo. Valencia: 1998, p. 97-103.

${ }^{64}$ La colección «Clásicos del Amor» se publicará, como otras tantas, tras la estela del éxito obtenido por la colección López Barbadillo. Cf. BLAS VEGA, José. «La «biblioteca de López Barbadillo y sus amigos»(1914-1924)». Cuadernos de bibliofilia, 1980, vol. 4, p. 43-62, esp. 50.

65 NÚÑEZ REY, Concepción. Carmen de Burgos, Colombine, en la Edad de Plata de la literatura española. Sevilla: 2005, p. 133-138. 
sibilitó el aprendizaje de las lenguas clásicas ${ }^{66}$, pero no se puede excluir que tuviera, ya en esta época, sus primeros contactos con las traducciones de los clásicos, por los que ya en los inicios de su carrera como escritora y conferenciante mostrará gran admiración ${ }^{67}$ y reivindicará la poesía de Homero y Virgilio - junto a la de otros modernos- como medio para encauzar el progreso del hombre. Tanto es así que, varios de los intelectuales del momento que glosan su figura la remiten al mundo de la antigüedad clásica, siguiendo el conocido tópico de la «mujer sabia»: Felipe Sassone se refiere a ella como «una griega» ${ }^{68}$ o Salvador Rueda le compone unos versos de alabanza comparándola con las más excelsas figuras de la mitología clásica, donde, entre otras cosas, se dice «se te creyera lira de Homero de humana y grandiosa» ${ }^{69}$; a todo esto se añaden los anhelos de la propia Carmen, que llegó a confesar: «soy una griega encerrada en un horroroso corsé moderno» ${ }^{70}$.

En cualquier caso, es evidente, ya como punto de partida, que la aproximación de Carmen a la obra de Longo no es la de una persona profesional de la filología griega, ni tan siquiera la de una helenista aficionada como lo fue Valera, y que la asignación de la traducción se debió a sus amistades en el círculo de Blasco Ibáñez, quien, no lo olvidemos, desde una postura programática, pretende hacer una colección de traducciones de clásicos llevadas a cabo por literatos, no por profesores ${ }^{71}$. Sin embargo, es justo señalar la honradez con que la autora manifiesta en el prólogo de la obra que «sin siquiera aparentar» haber recurrido al original griego pretende proporcionar al lector una versión «todo lo exacta posible» de la novela de Longo recurriendo a la

${ }^{66}$ NÚÑEZ REY, Concepción. Ibid., p. 63. El paralelismo a este respecto con otra gran autora, Emilia Pardo Bazán, con la que Carmen coincidió cronológicamente, y con quien compartió determinados planteamientos, es llamativo. Cf. HUALDE PASCUAL, Pilar. «La pervivencia de la novela griega en Emilia Pardo Bazán.....».

${ }^{67}$ En su propia autobiografía, Carmen se compara a «los héroes de Homero», teniendo sin duda en la cabeza la figura del errabundo Ulises, al hablar de los vaivenes a los que se vio sometida en sus relaciones con los demás: «Podría parodiar a los héroes de Homero «Reina en unas partes, mendiga en otras. Fui rica y carecí de todo. Vi alejarse a las gentes con la miseria...» (COLOMBINE. Autobiografía. Valencia: Prometeo, 1909, n. ${ }^{\circ}$ X, p.42)

${ }^{68}$ Cf. NÚÑ̃Z REY, Concepción. Ibid., p. 177.

${ }^{69}$ Poema publicado en el n. ${ }^{\text {o }}$ de abril de 1909 de la Revista Crítica. Cf. NÚÑ̃Z, REY, Concepción. Ibid., p. 220-223.

70 Sobre el conocimiento que la escritora adquirió sobre las grandes obras de la Literatura Universal y de Longo en concreto, en el círculo cultural de Gómez de la Serna, nos habla su coetáneo CANSINOS ASSENS, Rafael. La Novela de un Literato. Madrid: Alianza, 1996, p. 365.

${ }^{71}$ Recuérdese que esto mismo sucedió, entre otros casos, con la traducción de la Ilíada, rehecha sobre la francesa de Leconte de Lisle., Cf. HUALDE PASCUAL, Pilar. «Valoración de las traducciones de Homero en los siglos XIX y XX en España e Iberoamérica». En ÁLVAREZ MORÁN, Consuelo; IGLESIAS MONTIEL, Rosa María. Contemporaneidad de los Clásicos: la Tradición Grecolatina ante el Siglo XXI. Murcia: Universidad de Murcia, 1999, p. 369-377. 
versión francesa del obispo Amyot, completada por Courier con los pasajes hallados en el manuscrito completo. Pues bien, la autora almeriense emprende su traducción indirecta teniendo a la vista el texto de Amyot con los arreglos que hiciera el helenista Juan Pablo Courier, tal vez en la edición francesa de 1890 (Paris, Jules Tallandier), con ilustraciones de Rafael Collin y grabados de Champollion. Pese al admirable empeño de Carmen en acercar una obra del mundo clásico al pueblo, hay indicios de error que nos dan cuenta del carácter amateur de nuestra autora en lo que respecta al conocimiento de las traducciones previas, como el significativo hecho de que interpretara que el ilustrador del texto, Collin, era asimismo cotraductor del texto al francés.

La curiosidad me hizo buscar la versión francesa de Santiago Amyot, obispo de Auxerre, y los arreglos más recientes que han hecho el eminente Pablo Luis Courier (que la completó y corrigió) y Rafael Collín, para modernizar su ortografía y su lenguaje, sin menoscabo de su valor y sencillez ${ }^{72}$.

Por lo demás, el prólogo nos proporciona sustanciosos datos, como en el caso del de Valera, en primer lugar, sobre la idea de traducción que defiende la autora, en segundo lugar, sobre la idea que tiene de la naturaleza e historia de la novela y, finalmente, sobre su idea de relación entre moral y literatura.

En el primero de los temas tratados, su idea sobre la traducción, en realidad se articula en torno a la crítica de la versión de Longo hecha por Valera veintitantos años atrás. Para ello, Carmen ensaya una suerte de contestación a algunos párrafos del prólogo del autor de Pepita Jiménez, en concreto, a aquellos en que aquel se refiere a «arreglos» que ha hecho a la obra, y a su variación de «algunos lances sustituyéndolos por otros». Como en el caso de Valera, la autora hará una serie de consideraciones de índole literaria junto con otras de orden moral. Dentro de las primeras destaca, con una cierta ingenuidad filológica, el concepto de «traducción verdadera», que Carmen refiere sólo al contenido de la obra, cuando afirma que los traductores franceses «no omitieron ni variaron nada del original griego» y que, por tanto, la fidelidad al original lo garantiza «la versión francesa del obispo Amyot». En este mismo sentido cabe interpretar su crítica a la «concisión» de Valera, de la que tanta gala hacía el autor en su prólogo y que a Colombine, por comparación con la versión francesa, a veces le resulta oscura. Un ejemplo paradigmático lo tenemos en el pasaje de II.6 cuya traducción valerina critica nuestra autora por oscura, considerándolo muestra de que Valera «extractó en muchas ocasiones frases del original». Carmen da como fiel reflejo del original griego la traducción de Amyot que, vertida al español dice: «Existen estrechos en el mar que hasta hoy se llaman Bósforos, es decir, trayecto o paso de bueyes», frente a la de Valera que dice: «Hay muchos estrechos de mar que hasta hoy se llaman pasos de bueyes». Pues bien, acudiendo al original

${ }^{72}$ LONGO, Dafnis y Cloe. BURGOS, Carmen de (trad.). Valencia: Prometeo, 1910, p. VII, Los Clásicos del Amor. 
griego encontramos, lo que nos hace ver que la traducción de Valera es de una absoluta fidelidad al original, mientras que en la de Amyot, amén de la supresión del adjetivo, encontramos una amplificación evidente.

En lo que respecta a las cuestiones morales, Carmen tiene la intuición de lo que luego será la necesaria separación entre moral y literatura, al afirmar que «nadie tiene derecho a omitir y menos a cambiar nada de lo que un autor ha escrito, sobre todo si es antiguo». Desde este planteamiento criticará la incoherencia de Valera al defender la moralidad de la obra «no sabemos por qué ni para qué». Sin embargo, no deja la autora de manejar conceptos como pureza o inocencia, al reseñar que lo descarnado de los términos empleados o el realismo sensual de las escenas de la novela se separan de cualquier impureza, en su afán en destacar la inocencia de su intención y, de nuevo, tiene el valor de la modernidad en su intuición de no interpretar una obra antigua fuera del contexto y de las convenciones de la época en que fue escrita. Resulta, asimismo relevante la insistencia en que aun las escenas más crudamente eróticas de la obra no pretenden despertar ningún tipo de sentimiento libidinoso, ya que, en este punto, la autora no puede evitar una velada alusión a la novela sicalíptica ${ }^{73}$ del momento cuando disocia Dafnis y Cloe del «sentimiento impuro que pudieran despertar las narraciones artificiosas escritas a impulsos del espíritu mercantil en la literatura». En definitiva, $D a$ fnis y Cloe es belleza y no carne de mercado editorial.

En tercer lugar, como también hiciera Valera en su momento, el prólogo a la obra de Longo le sirve a Carmen para apuntar una serie de consideraciones sobre el género novelesco en su conjunto. La novela será, en opinión de nuestra autora, la cumbre de la evolución de los géneros literarios y, dentro de ello, las más altas cotas están reservadas para la llamada novela social. La misión del escritor-artista es, en opinión de nuestra autora, una suerte de sacerdocio marcado por la rebeldía, por la denuncia plasmada en la pintura de la realidad. Dafnis y Cloe, pese a alejarse, como novela pastoril que es, de la realidad social del momento, sobrevive, siempre válida, por su belleza ligada a los «elementos pasionales». En un salto anacrónico, Carmen define la no-

73 Para el carácter de término inventado en la Edad de Plata y la falta de definición concreta y su inclusión en los Diccionarios de la Real Academia de la lengua desde 1902 cf. GALEOTE, Manuel. «Bohemia y sicalipsis, mucho más que dos palabras». En CRUZ CASADO, Antonio (coord.). Silva Literaria de Varia Lección: (de Cervantes a Valera), in memorian Matilde Galera Sánchez. Lucena: Ayuntamiento de Lucena, 2006 especialmente p. 248, 264 y 273; por su parte ZUBIAURRE, Maite. En «Serrallos, sicalipsis y máquinas de escribir: erotismo, exotismo y modernidad en España». Romance Quaterly, 2005, vol. 52, n. ${ }^{\circ} 3$, p. 215, nota 2 , reseña el uso del término sicalipsis y de su adjetivo derivado para designar tanto a la literatura erótica en general, como a las manifestaciones artístico-sensuales de los años veinte y treinta del siglo XX. Académicamente se intentó buscar una etimología culta del término sicalipsis partiendo del griego 'higo', y 'acción de untar, frotar', que no dejara lugar a dudas sobre la intención y características de este género de novelas. Actualmente, a esta rebuscada etimología no se le da credibilidad. 
velita de Longo como adscrita al género «que ahora se cultiva con el nombre de naturalista», y justifica esta afirmación la verosimilitud exigible al género en función, de nuevo, de la consideración del texto en su contexto, de las condiciones y necesidades de la época en que se escribió. Carmen lo interpreta en los términos de las corrientes literarias que admira y a las que, de alguna manera, se adscribe, como es la descripción naturalista combinada con una cierta introspección psicológica ${ }^{74}$.

En definitiva, si tenemos que resumir la actitud de Carmen de Burgos respecto Dafnis y Cloe tenemos que señalar tres rasgos: la ingenuidad filológica en su aproximación a la obra, la intuición novedosa de la consideración del texto en el contexto en el que nace, con la consiguiente necesidad de separación entre moral y literatura, y una cierta candidez tendenciosa en su catalogación de la obra de Longo como novela naturalista.

6. DAFNIS Y CLOE EN LA NOVELA LÍRICA: DE «EL EXCÉNTRICO DEL 98», A DOS AUtORES NOVECENTISTAS. LOS TRABAJOS DEL INFATIGABLE CREADOR PÍO Cid, DE Angel Ganivet, Las nOVElas de URbano Y Simona de Ramón PÉREZ DE AyAla Y LA OBRA DE GABRIEL Miró

La traducción de Colombine, no alcanzó, desde luego, la popularidad de la de su precedente y paisano Valera, ni dejó un eco similar en los escritores de su generación. Sin embargo, dentro del campo de la génesis literaria, la novela de Longo seguirá siendo referencia recurrente en algunos novelistas de entre siglos que, aun perteneciendo a generaciones y estéticas muy diferentes, tienen en común componer lo que se ha venido a llamar «novela lírica», aquella en la que el autor refleja de alguna manera su propia experiencia vital. Una de las características que tienen en común estos autores es su mucho más cercano contacto con la lengua griega que los que les habían precedido. Si seguimos un orden cronológico, hemos de empezar con el caso muy peculiar de Ângel Ganivet, al que se ha llegado a llamar «el excéntrico del 98». Las referencias de Ganivet a Dafnis y Cloe aparecen en su obra Los Trabajos del Infatigable Creador Pío Cid, en una ocasión como referencia de lectura y, a partir de aquí, en uno de los poemas del autor que en la ficción aparecen escritos por mano del protagonista. La mencionada referencia de lectura se produce entre el protagonista de la obra (y controvertido alter-ego el autor ${ }^{75}$ ) y una otoñal y frívola duquesa, madre del pupilo de Cid. La dama, coqueta, anima a Pío a escribir una obra imperecedera y le pone como modelo, precisamente la novela de Longo. El pasaje es el siguiente:

${ }^{74}$ Cf. NÚÑEZ REY. Ibid. , p. 137.

${ }^{75}$ Sobre la autoficción en la obra de Ganivet y las diferentes facetas de su personalidad reflejadas en sus personajes cf. PUERTAS MOYA, Francisco Ernesto. La Identificación Autoficticia de Ángel Ganivet. Logroño: SERVA, 2004. 148 p. 
«(...) decía que usted debía ser autor, pero no para romper sus obras. Si usted escribiera un libro que se hiciera famoso... Vea usted algo que no muere tan fácilmente. No es menester que fuera un libro grande. A mí las obras largas me horripilan. Un libro como este que yo leo ahora y que es uno de mis favoritos. ¡Cuántos siglos hace que le escribieron y se lee siempre con el mismo encanto!... - dijo tendiendo a Pío Cid el precioso volumen, que era una edición francesa ilustrada de la Pastoral de Longo-. ¿Conocerá usted el Dafnis y Cloe, sin duda?

—Lo leí hace muchos años — contestó Pío Cid cogiendo el libro-. Aunque a usted le desagrade oírlo, le diré que no es santo de mi devoción. Es demasiado femenino o afeminado, es una obra de decadencia.

- ¡No diga usted eso, por Dios! Es un idilio delicado y con un perfume silvestre que encanta.

-A mí me parece una imitación sensual y profana de la historia de Adán y Eva. Sólo que la serpiente engañó a la mujer para que ésta engañase al hombre, y Liconia (creo que se llama Liconia la mala mujer que interrumpe el idilio) engaña al hombre para que éste engañe a la mujer.

- No había oído jamás esa comparación, y no deja de ser curiosa.

- Si quiere usted se la escribiré en unos versillos que se me ocurren ahora mismo. Usted cree que yo debo de ser poeta....

Cloe es la flor ideal que va a nacer

En Dafnis, tallo tierno y floreciente;

Liconia es la fatídica serpiente

(Primera arruga en rostro de mujer)

Que arrastra con sigilo su impureza

Y se oculta en lo oscuro cautelosa,

Como eterno traidor, que, generosa,

Abriga entre sus pliegues la belleza» ${ }^{76}$.

Desde luego, cabe pensar que en la contraposición de gustos estéticos de Pío Cid y la duquesa subyace más que una mera anécdota. Varias cosas pueden plantearse: en primer lugar, si la opinión acerca de la obra de Longo expresados por Pío Cid, corresponde con la de Ganivet y si, en ese caso, hay factores psicobiográficos que le hayan llevado a ella. En primer lugar, hemos de reseñar que en el autor granadino encontramos no un simple aficionado a las letras clásicas, sino un helenista que no pudo llegar a ejercer como tal. Es sabido cómo Ganivet cursó estudios de Lengua y Literatura Griega en la Universidad de Granada, donde fue discípulo del célebre helenista González Garbín, cómo destacó por sus calificaciones en Latín y Griego y cómo terminó doctorándose en la Universidad Central con una tesis sobre la importancia de la Lengua Sánscrita ${ }^{77}$. Es también notable el disgusto que le supuso la no obtención de la cátedra de griego de Granada, a la que optó en junio de 1891, y que ganó su contrincante Ale-

${ }^{76}$ GANIVET, Ángel. Los Trabajos del Infatigable Creador Pío Cid. MONTERO PADILLA, José (ed.). Madrid: Castalia, 1998, p. 479-480.

${ }^{77}$ Recientemente reeditada por GARCÍA MARCOS, Francisco José, GANIVET, Ángel. Importancia de la lengua sánscrita: y servicios que su estadio ha prestado a la ciencia del lenguaje en general y a la gramática comparada en particular. Almería: Universidad de Almería, 2005. 
many. Pues bien, entre los seis miembros del tribunal se encuentra Don Juan Valera, nuestro traductor patrio de las Pastorales de Longo. Tal vez en la consideración literaria de esta obra expresada por el sobrio personaje de Pío Cid, en su catalogación de obra «afeminada» y de «decadencia», está vertida la posición de Ganivet, a la que no sería ajena, amén de su talante personal, una cierta crítica al egabrense, de quien sabemos que, aunque recibió recomendación para apoyar la candidatura de Ganivet a la cátedra de Granada, puso reparos para prestarle su apoyo, según se deja ver en su carta a Juan Facundo Riaño, fechada en 19 de junio de 1891:

En el caso del Sr. Ganivet, que usted me recomienda, debiera Vd. Contar conmigo si dependiese de mi voluntad el hace lo que Vd desea; pero, desgraciadamente, no depende, y, (lo digo con sigilo y a fin de que no le sorprenda luego) me parece que el tribunal está muy inclinado a favor del otro opositor, hombre sin duda de mérito extraordinario. Recelo, pues que el Sr. Ganivet [...] sólo tendrá el segundo lugar. Aún así, si no con todo el provecho, a que él aspira, el Sr. Ganivet saldrá muy airoso y con brillante concepto de las oposiciones. Siento no poder augurar ni prometer más...» ${ }^{78}$.

Y es sabida también la profunda decepción del autor granadino ante este primer fracaso y sus palabras críticas respecto a la mencionada oposición:

Si me diesen diez millones y la seguridad de ser catedrático en la Central, no entraría más en oposiciones a cátedras... En cuanto a lo que pasa con el catedrático de griego, de sobra lo sabía yo, aunque no he querido nunca hablar porque no tomasen la cosa a despecho... Las oposiciones... consistieron en ejercicios de fuerza bruta... ${ }^{79}$.

Por otra parte, en la postura de la frívola duquesa que da réplica al Pío Cid de la obra ganivetiana se dejaría translucir la opinión expresada por el propio Valera en el prólogo de su traducción, pues su denominación de las Pastorales como «idilio en prosa» y del amor de los pastores lesbios como «afecto bastante delicado», encuentra correlato en las palabras de la duquesa al calificar a la obra de Longo como «idilio delicado». Y es que en las vidas tan paralelas de estos dos andaluces, helenistas frustrados, novelistas y diplomáticos en los confines de Europa, se enfrentan dos maneras antagónicas de ver el mundo, la optimista y ligera del cordobés y la individualista, sobria, nihilista y atormentada del granadino, que se polarizan, en este caso, en su

78 ROMERO TOBAR, Leonardo. «Cartas de Juan Valera a Juan Facundo Riaño». Angélica, 1994, vol. 6, p. 136. Sobre la falta de incondicionalidad demostrada por Valera en este y otros casos cf. ROMERO TOBAR, Leonardo. Ibid., p.132.

${ }^{79}$ Cf. FERNÁNDEZ GALIANO, Manuel. «En el centenario de Ángel Ganivet». Estudios Clásicos, 1966, vol. X, p. 214-219. Pese a esta afirmación, si admitimos que los personajes autoficticios de Ganivet representan en ocasiones proyecciones de los deseos frustrados del autor, sería significativa la aparición del personaje de don Gonzalo Fernández, filólogo clásico que aparece en el relato «Academia de los Nocturnos». Cf. PUERTAS MOYA, Francisco Ernesto. Ibid., p. 43-44. 
apreciación de la novela de Longo ${ }^{80}$. Pero, sobre todo, la mención de Dafnis y Cloe en Los Trabajos debe interpretarse a la luz del amor fatal por Masha Diakovsky, en el que se vio sumido nuestro autor en los últimos años de su vida. Si nos atenemos a algunas interpretaciones de especialistas en la vida y en la obra de Ganivet, en la figura de la duquesa de Almadura se escondería la persona de Masha, con quien Ganivet no pudo llegar a consumar su pasión reprimida y quien, como el personaje de la duquesa, inició una relación con otro amante ${ }^{81}$. Significativo es, en este punto, que el escritor le enviara a la finlandesa un poema en francés, fechado el 5 de agosto de 1896, que es una variación del de Dafnis y Cloe que Pío Cid dedica a la duquesa de la novela:

Daphnis est l'abre pas encore fleuri,

Chloé la fleur idéale qui désire maître,

Licaenium le serpent, l'éternel traîte

Caché de la beauté dans les replis.

Je voudrais voir de roses plein mon jardin,

Chargés de fruits superbes mes fruitiers

Sans sentir l'odeur puante du fumier;

Tout cela fait par quelque ouvrier divin.

Mais nous sommes des enfants, nous ignorons

L'essence des choses - a dit un poète sage:

Tu tues les pauvres vers, comme un sauvage

Et après tu veux trouver des papillons! ${ }^{82}$

La primera estrofa, tan parecida a la del poema inserto en la novela de Pío Cid, desarrolla de nuevo el tema de la arruga — señal de prematura vejez-y el de la tentación y el pecado. Pero es, tal vez, en la segunda estrofa donde se transparenta el drama de la ambigüedad de sentimientos del autor, su erotismo frustrado y reprimido ${ }^{83}$, puesto de relieve en el deseo de flores y frutos (amor espiritual) sin tener que sentir el «hedor del estiércol» (sexualidad). A la luz de la lectura de este poema parece inevitable interpretar que en las palabras de Pío Cid se refleja el rechazo del propio Ganivet a la sensualidad explícita de la obra de Longo $^{84}$.

${ }^{80}$ Cf. Aunque en 1895, Ganivet enviará desde Amberes a su amigo Nicolás María López, entre otras obras como el Cándido de Voltaire o los Cuentos de La Fontaine, un ejemplar de Dafnis y Cloe. Cf. GALLEGO MORELL, Antonio. Ángel Ganivet, el Excéntrico del 98. Madrid: Guadarrama, 1974, p. 105.

${ }^{81}$ A finales de 1896 Masha inicia una relación con el pintor Edelfelt. Cf. WISS, Roberto y Marjatta. Angel Ganivet in Finlandia. Helsinki: Société Néophilologique, 1988, p. 40.

${ }_{82}$ Cf. WISS, Roberto y Marjatta. Ibid. p. 58.

${ }^{83}$ Cf. PUERTAS MOYA, Francisco Ernesto. Ibid., p. 998-1001.

${ }^{84}$ El testimonio de la carta que Ganivet envía a su amigo López el 18 de septiembre de 1895, abunda en este sentido, ya que el granadino envía la novela a su amigo, pero no la traducción de Valera, sino una versión francesa en cuatro tomos «para muestra (y que por desgracia todos son assez indécents)...Dafnis y Cloe, traducción casi literal (para que leas 
En los años iniciales del siglo XX, dentro de la llamada «generación del 14» o corriente del Novecentismo, vuelve a presentarse de forma poderosamente intertextual la novela del autor de Lesbos. Su manifestación está en dos de los principales representantes de la denominada «novela lírica», Gabriel Miró y Ramón Pérez de Ayala. No es de ninguna manera anecdótico el hecho de que ambos autores pasaran algunos años de su infancia formándose en colegios de jesuitas, donde recibieron una buena iniciación en las Humanidades Clásicas y, a la vez, una férrea disciplina y una fuerte represión sexual que se hará notar, aun con características muy diversas en cada uno de ellos, al tratar el tema amoroso en distintos aspectos de su obra.

Por lo que respecta a Miró, su estancia en el colegio de Santo Domingo de Orihuela, regido por los jesuitas, entre los ocho y los doce años, le permitió iniciarse en las lenguas latina y griega ${ }^{85}$ y en el gusto por los autores clá$\operatorname{sicos}^{86}$, especialmente los griegos, entre los que confesaba preferir a Safo, Píndaro, Teócrito y Longo. A ellos deseó volver en la edad adulta y quiso degustarlos en lengua original, ya que, según él mismo afirmaba, «conocía muchos autores griegos y latinos (traducidos, pues olvidé estas lenguas) ${ }^{87}$. Como el repaso de los conocimientos de griego adquiridos con los jesuitas le era difícil, buscó un profesor que le ayudase y no pudo encontrarlo. Sin embargo, la lectura de Longo emerge en varios lugares de su obra en los que se hace referencia al descubrimiento del erotismo. El caso más significativo aparece en la obra de claro contenido autobiográfico titulada Niño y Grande, ejemplo de novela de formación en la que la iniciación en la sexualidad del protagonista Antón Hernando contiene elementos implícitos y explícitos de la obra de Longo: el adolescente, Antón, trasunto literario del autor, interno en un colegio de jesuitas y enamorado de forma infantil e idealizada de Elena, hermana de un compañero de internado, experimenta prematuramente el despertar de la libido por la broma pesada de unos compañeros, y describe su inocente primer sueño erótico remitiendo a la actitud sensualmente ingenua de los literarios pastorcillos lesbios:

Que apenas me rindió el sueño, lo tuve de honestísimas delicias, porque, sin sortilegios ni diabólicas artes, no subió, sino que descendió a mi lado la hermanita de Bellver, desnuda y casta como una tibia escultura, y estuvimos juntos, lo mis-

en su integridad escabrosa, lo que en la traducción española suele omitirse)». Cf. WISS, Roberto y Marjatta. Ibid., . p. 39.

${ }^{85} \mathrm{Al}$ parecer cursó $1^{\circ}$ de latín en el año 1889 y $2^{\circ}$ de Latín (que incluía $1^{\circ}$ de Griego) en 1890. Cf. KING, Edmund L. Sigüenza y El Mirador Azul y Prosas de El Ibero, Introducción biográfica, transcripciones y enmiendas por.... Madrid: ed. de la Torre, 1982, p. 43.

${ }^{86}$ «Fue muy provechoso a su formación su temprano encuentro con los autores griegos y latinos que le introdujeron en el mundo clásico». Cf. CARPINTERO, Heliodoro. Gabriel Miró en el recuerdo. Alicante: Universidad y Caja de Ahorros Provincial, 1983, p. 27.

${ }^{87}$ Citado por GONZÁLEZ BLANCO, Andrés. En Los Contemporáneos. $1^{a}$ serie. París: s.f.; tomo el texto de RAMOS, Vicente. Vida de Gabriel Miró. Alicante: Diputación de Alicante, 1996, p. 41. 
mo que Dafnis y Cloe, antes de que el pastor recibiese enseñanzas de la taimada Lycenia $^{88}$.

Pero no sólo en esta mención explícita se deja ver la presencia de Longo. Dentro del desarrollo de la trama, el aún adolescente Antón es iniciado en el sexo por el personaje femenino de doña Francisca, paralelo al de la «taimada Lycenia» de Longo mencionada por el alicantino. En efecto, Licenion es una mujer hermosa, casada con un viejo que no la satisface sexualmente y doña Francisca, bella y voluptuosa también, se ve frustrada por la falta de descendencia, que ella atribuye a la edad avanzada de su esposo. Ambas utilizan a los respectivos jóvenes para intentar saciar una necesidad que sus circunstancias les habían impuesto. Aún más, en los pasajes de ambas obras se aprecia la presencia un ave, el ganso, posible símbolo erótico, como detonante que facilita la relación adúltera: en la novela del griego, Licenion pide a Dafnis ayuda para rescatar a uno de los gansos de su manada que un águila le ha arrebatado; en el caso de la novela del alicantino, el joven Antón Hernando devuelve un ganso escapado al marido de la que será su amante.

Con tal propósito, salió al día siguiente, como para ir a ver de nuevo a la partida, y se fue derecha a la encina donde Dafnis y Cloe se sentaban. Fingiéndose con primor toda consternada. «iSálvame — dijo—, oh, Dafnis! ¡Ay, infeliz de mí! ¡Un águila me ha robado el más hermoso de mis veinte gansos! Fatigada con tal peso, no he podido volar hasta lo alto de aquel peñón, donde anida, y se bajó con su presa a lo hondo del soto. Te lo ruego por Pan y las Ninfas: entra conmigo en la espesura; liberta mi ganso» ${ }^{89}$.

«Pasé a la confianza del hidalgo porque le devolví un ganso que se la había escapado, saltando por la leña amontonada de su huerto-corral, paredaño del nuestro ${ }^{90}$.

Parece, en cualquier caso, evidente que la novela de Longo, como relato de iniciación amorosa, está en la memoria de Miró ${ }^{91}$ al crear la historia de Antón Hernando, aunque el desarrollo final de la trama difiera radicalmente del de la obra griega.

Pero no pararán aquí las alusiones de Miró al texto del escritor de Lesbos, sino que, en otro relato escrito por las mismas fechas ${ }^{92}$ - en el que, por

\footnotetext{
${ }^{88}$ Miró, Gabriel, Niño y Grande. RUIZ SILVA, Carlos, (ed.). Madrid: Castalia, 1988, p. 96.

${ }^{89}$ Dafnis y Cloe, libro III, traducción de Juan Valera.

${ }^{90}$ MIRÓ, Gabriel. Niño y Grande. RUIZ SILVA, Carlos (ed.). Madrid: Castalia, 1988, p. 113

${ }^{91}$ Incluso en otro pasaje de la obra, al mencionar la actitud provocativa del personaje adúltero de Amelia, compara al campesino al que ella sacó a bailar con uno de los personajes de la obra griega: «escogiendo de pareja a un mozo de ruda hermosura, como un pastor de Longo». Ibid., p.183.

${ }_{92}$ Para las fechas probables de gestación de El Hijo Santo, que vendrían a coincidir con las de Amores de Antón Hernando, primera versión de lo que luego sería Niño y Grande. Cf. ALTISENT, Marta T. «El hijo santo» de Gabriel Miró: Técnicas de reducción y condensación». Anales de Filología Hispánica, 1990, vol. 5, p. 86 y n. 3.
} 
cierto, se presenta el tema del clérigo enamorado en un entorno bucólico, en el que emerge el modelo de Pepita Jiméne $z^{93}$ - al describir un pasaje de cierta proximidad entre el presbítero y la viuda compara el pudor de ésta con el de la cándida pastora de la novela griega:

El maestro la toma ( $s c$. una amapola); y el discípulo le pide que la prenda en los cabellos de la madre. Ella, risueña, finge reprender la imprudencia. Las mejillas del presbítero se inflaman; doña María ríe infantilmente; y el hijo insiste aplaudiendo gozoso y picaresco (...) A D. Ignacio le golpea el corazón como en trance de pecado, y se le nubla el pensamiento y la mirada; y doña María, pueril, con inocencia y rubores de Cloe, le presenta su adorable cabeza.... ${ }^{94}$.

Sin embargo, pese a que Miró emplea estas referencias a los personajes de Longo para dibujar el paso del amor infantil al amor adulto en Niño y Grande, y la toma de conciencia de una pasión prohibida en El hijo santo, la concepción del erotismo en ellas será muy diferente, tanto de la del autor griego como, en el caso de esta última obra, de la que presenta Valera en su Pepita Jiménez, con sus amables historias amorosas de final feliz. Frente al autor cordobés, que resuelve el conflicto entre religión y sexualidad y lo plasma simbólicamente en la fusión de paganismo y cristianismo presente en las obras de arte que adornan la casa de los protagonistas tras su matrimonio, en Miró, el Antón Hernando de Niño y Grande no podrá ver colmado su amor por Helena, casada y fiel a su esposo, y la pasión sentida desde la infancia acabará en fracaso, mientras que para Ignacio, el sacerdote de El Hijo Santo, la renuncia a su pasión en aras de un ideal impuesto supondrá en principio un desengaño que le llevará a la posterior degradación moral. Ambos desenlaces, fracaso y degradación, así como la recurrente presencia del dolor y la enfermedad asociada a la experimentación del sentimiento amoroso, suponen una solapada expresión del conflicto entre erotismo y religión, que no llega, en ningún caso a censura explícita ${ }^{95}$.

Si las referencias de Gabriel Miró a Dafinis y Cloe suponen una intertextualidad literaria que no se emplea con intención argumentativa, no es el caso de su coetáneo Pérez de Ayala, quien, desde una postura anticlerical volverá los ojos a la novela de Longo para hacer una crítica mordaz sobre la represión sexual al narrar la historia de Urbano y Simona en sus novelas Luna de

${ }^{93}$ Sobre los modelos valerinos de esta obra y la admiración que Miró sintió por el egabrense cf. ALTISENT, Marta T. Ibid., p. 92.

${ }_{94}$ MIRÓ, Gabriel. El Hijo Santo. Madrid: Los Contemporáneos, 1909, n. ${ }^{o} 24$ p. 13.

${ }^{95}$ Sus biógrafos insisten en que, pese a la tristeza con que recordaba los años de internado, jamás hizo crítica explícita ni del colegio, ni de la Compañía. Su amigo Figueras Pacheco afirmaba que a su estancia en el internado debía Miró los elementos básicos de su formación: «Yo debo hacer constar que nunca le oí palabras que implicasen quejas o censuras, sino de respeto, cuando no de elogio, para los jesuitas». Cf. FIGUERAS PACHECO, Francisco. Orto literario de Gabriel Miró. En los linderos de la selva. «Sigüenza». Sigüenza 1. Alicante: 1952, cap. XII, p. 6-7. 
Miel, Luna de Hiel y Los trabajos de Urbano y Simona (1923) ${ }^{96}$. El autor, entusiasta de la lengua griega, en la que se había iniciado en sus años juveniles con los jesuitas y cuyo conocimiento había posteriormente ampliado mediante asistencia a las clases que impartía Julio Cejador en Oviedo ${ }^{97}$, ironiza, partiendo de la novela griega, sobre la falsa moral y los prejuicios sociales en torno a la sexualidad, en una sociedad que, al menos en este punto, ha roto con la naturaleza. Sus protagonistas, enamorados desde la infancia como Dafnis y Cloe, llegan a la edad adulta, de forma inverosímil y grotesca, desconocedores de la mecánica del sexo y de la procreación. El matrimonio, pactado por las madres de ambos, aunque celebrado, no llega a consumarse por la ignorancia de los jóvenes, cual si se tratase de los amantes de Lesbos. Precisamente a ellos hace referencia en varias ocasiones el autor por boca de don Cástulo, erudito estudioso de mundo antiguo, profesor de letras humanas y tutor del joven Urbano, que los denomina como «Dafnis y Cloe redivivos». Éste representa una visión realista del mundo y del amor, frente a la visión idealizada de doña Micaela, madre del muchacho y responsable de la increíble ignorancia sexual que le aqueja y que conscientemente ha propiciado la dama, por su patológico rechazo a la sexualidad, al amor físico. Como si se tratara de una pareja protagonista de novela griega, los jóvenes enamorados también tienen su jardín idílico, comparten la turbadora sensación del primer beso e intuyen el valor simbólico de la desnudez en su proceso de transición de la inocencia al conocimiento, pero también tendrán que soportar la separación y diversos contratiempos, los «trabajos» a que hace alusión el título, a lo largo del transcurso de las lunas y de las estaciones del año ${ }^{98}$. El final feliz y la consumación del matrimonio nos remiten también a la novela del de Lesbos. Se puede decir que Pérez de Ayala utiliza el antiguo tema de la obra de Longo para retomar el lema Artis natura magistra o, más aún, Vitae natura magistra.

\section{DAFNIS Y CLOE EN LAS VANGUARDIAS ESPAÑOLAS: LA GENERACIÓN DEL 27}

Tenemos testimonios del aprecio que distintos escritores ligados al la Generación del 27 dispensaron a la obra de Longo. Así, sabemos que Rafael Alber-

${ }^{96}$ La vinculación con la obra de Longo ya en TREND, John Brade. «Pérez de Ayala, Daphnis and Chloe, and the Jesuits». En: Alfonso the Sage and Other Spanish Essays. Londres: Constable \& Company Ltd., 1926, p. 117.

${ }^{97}$ Para la influencia que en el aspecto humanístico de Pérez de Ayala también tuvo Rafael Zamora, marqués de Valero de Urría, cf. LOZANO MARCO, Miguel Ángel. Del Relato Modernista a la Novela Poemática. La Narrativa Breve de Ramón Pérez de Ayala. Alicante: Caja de Ahorros provincial de Alicante, 1983, especialmente p. 93.

${ }_{98}$ Cf. GULLÓN, Rafael. «Ramón Pérez de Ayala y la novela lírica». En: FERNÁNDEZ, Pelayo H. (ed.); Simposio internacional Ramón Pérez de Ayala. Méjico-Gijón: Nuevo México-Universidad de Gijón, 1981, p.64. 
ti, entre las lecturas de clásicos grecolatinos que emprende en 1939 y que determinarán una nueva sensibilidad en su obra poética posterior, está Dafnis y Cloe, en la entonces reciente edición francesa de Les belles lettres (1933) ${ }^{99}$. Asimismo, Federico García Lorca, en una entrevista de 1934, asocia un recuerdo de infancia con la novela de Longo: mientras araban en el campo, la hoja del arado saca a la luz un mosaico romano. Federico, tras describir el efecto de la hoja del arado al penetrar en tierra afirma lo siguiente:

\begin{abstract}
Me gustaba ver cómo la enorme púa de acero abría un tajo en la tierra, tajo del que brotaban raíces, en lugar de sangre. [...] Tenía una inscripción que ahora no recuerdo, aunque no sé por qué acude a mi memoria el nombre de los pastores Dafnis y Cloe. Ese mi primer asombro artístico está unido a la tierra. Los nombres de Dafnis y Cloe tienen también sabor a tierra y a amor. Mis primeras emociones están ligadas a la tierra y a los trabajos del campo Por eso hay en mi vida un complejo agrario, que llamarían los psicoanalistas ${ }^{100}$.
\end{abstract}

Estas palabras del autor del Romancero Gitano han sido evocadas en distintas ocasiones, precisamente en clave psicoanalista para hacer referencia tanto a cuestiones artísticas como al erotismo ${ }^{101} \mathrm{e}$, incluso, a la represión de la homosexualidad $^{102}$.

Ciertamente connotaciones subliminales debe de tener también la mención que, otro compañero de generación, Benjamín Jarnés hace de la obra de Longo en «El amor en la novela». Allí la ofrece como ejemplo de novela en la que «el amor acapara toda la atención», frente a la «gran novela inicial de nuestra cultura» - la Ilíada - y hace una lírica contraposición entre la sangre de los guerreros derramada a causa de la rivalidad por una mujer y la sangre de la desfloración femenina ${ }^{103}$ :

En la primera el amor figura como galardón por merecer, en la segunda, el amor es apenas una flor más por deshojar. El amor en la Ilíada baña en sangre ejércitos y reyes, porque la gran coquetería de Helena así lo quiso; en el dulce idilio de Cloe no hay más sangre que la que brota de un clavel hendido ${ }^{104}$.

${ }^{99}$ Cf. COLINAS, Antonio. Rafael Alberti en Ibiza: Seis semanas del verano de 1936. Barcelona: Tusquets, 1995, p. 134.

100 GARCÍA LORCA, Federico. Obras Completas. GARCÍA POSADA, Miguel (ed.). Barcelona: Galaxia Gutenberg, 1997, vol. III, p. 526-527.

101 «Como el arar, la unión de amor y la escritura supone una penetración o inscripción de la que brotan la sangre o las palabras con las que configurar la verdad vivida. La pasión y la escritura son actividades donde la alegría se funde con el dolor, sin el cual perderían su verdadera identidad». Cf. NEWMAN, Candelas. Lorca, una Escritura en Trance. Amsterdam / Philadelphia: John Benjamins Publishing Company, 1992, p. 95.

${ }_{102}$ Desarrollado sobre todo por SAHUQUILLO, Ángel. Federico García Lorca y la Cultura de la Homosexualidad. Estocolmo: Stockholms universitet, 1986, p.195.

${ }^{103}$ JARNÉS, Benjamín (ed.). Elogio de la Impureza. Invenciones e Intervenciones. Madrid: Fundación Santander Central Hispano, 2007, p. 371.

${ }^{104}$ La mención a esta sangre sólo aparece en la obra de Longo por boca de Licenion en el libro III, quien previene y aconseja a Dafnis de esta manera: «Cuando Cloe empren- 
Pero si hay un autor de esta generación que realmente llevó Dafnis y Cloe a la vanguardia de las letras españolas, este es Mauricio Bacarisse. En él se dan, como sucedía con Valera y con Ganivet, las circunstancias conjuntas de ser creador y conocedor de la lengua griega. Su sólida formación, producto de haber cursado el bachillerato francés y de su licenciatura y doctorado en Filosofía y Letras por la Universidad Central, probablemente propició su gusto por la literatura de la antigua Hélade, a la que tuvo acceso en lengua original, hasta el punto de haber llevado a cabo dos traducciones de obras clásicas: el Edipo Rey de Sófocles y el Critón de Platón ${ }^{105}$. La primera vez que Bacarisse vuelve los ojos al mundo clásico a la hora de elaborar su obra poética es en 1923, momento en el que publica, precisamente bajo el epígrafe general de Dafnis y Cloe, tres poemas con referencia a este clásico en la $R e$ vista de Occidente XI, 33, de marzo de 1926: Las cunitas, La casa mala y Luna de miel. En ellos trata temas básicos de la novela de Longo, empleando, por ejemplo, el nombre de los amantes de Lesbos para desarrollar la contraposición entre juego infantil y satisfacción del deseo sexual, como símbolo del paso de la infancia a la adolescencia, así como se puede ver en un párrafo tan significativos como el siguiente:

Sus juegos eran infantiles y propios de zagales. Ora ella, con juncos que cogía, formaba jaulas para cigarras, y, distraída en esta faena, descuidaba el ganado. Ora él cortaba delgadas cañas, les agujereaba los nudos, las pegaba con cera blanda, y se esmeraba hasta la noche en tocar la zampoña. [...]. En suma, más bien se hubieran visto las cabras y las ovejas dispersas que a Dafnis y Cloe separados. En medio de tales juegos, Amor empezó a darles penas ${ }^{106}$.

da contigo este combate se quejará y llorará y yacerá como muerta, llena de sangre. Pero tú no te asustes por la sangre, sino que, cuando la convenzas para que se entregue a ti, tráela a este lugar, para que, aunque grite, nadie la oiga, y aunque llore, nadie la vea y aunque sangre pueda lavarse en la fuente.» (En este caso, la traducción es nuestra).

${ }^{105}$ La traducción de Edipo Rey la hizo en colaboración con Fernández Adarvín, pero la parte principal del trabajo recayó sobre Bacarisse, siendo Adarvín simplemente el revisor. La obra que se publicó, sin año, en la editorial Espasa-Calpe, no tiene prólogo, ni notas y está traducida en verso. Al parecer data de en torno a 1925. Según Roberto Pérez, entre los papeles del autor, conservados por la familia, aparecen diversos fragmentos de esta traducción. Cf. PÉREZ, Roberto. Vida y obra de Mauricio Bacarisse. Estudio de la obra poética. Barcelona: Universitat de Barcelona, 1986, p.14. La otra traducción directa del griego que realizó nuestro autor quedó inédita y fue una traducción del mencionado diálogo platónico para su representación teatral en la sección de filosofía del Ateneo de la que Bacarisse era secretario. La representación se llevó a cabo el 24 de mayo de 1923, sobre la traducción de Mauricio Bacarisse y H. R. Romero Flores con la actuación de Enrique Borras y Ruiz Tatay. La prensa se hizo eco de esta actividad cultural alabando la labor de los organizadores-traductores sobre los detalles de la elaboración del trabajo cf. PÉREZ, Roberto. «Mauricio Bacarisse y el teatro». Actas del X Congreso de la Asociación Internacional de Hispanistas. Barcelona: PPU, 1989, pp. 177-178.

${ }^{106}$ Dafnis y Cloe, libro I, traducción de Juan Valera. 
Pero en el poema de Bacarisse los juegos de pastores se han trocado en un juego muy popular en los años veinte, «las cunitas», en el que demuestra la habilidad manual de dos jugadores que hacen figuras pasándose alternativamente una cuerda entre sus dedos. En la elaboración poética de Bacarisse, la cuerda del juego que distrae a Cloe de su posible actividad sexual pasa a ser un rayo de luz ( «Con una hebra de luz / Cloe quiere hacer cunitas / ¿Por qué te distraes en eso/ en tan dulce compañía?»), mientras que el agreste paisaje de Lesbos se actualiza en el marco del lecho y el agua omnipresente en la novela - y en todo locus amoenus clásico- pasa a ser «una concha de agua pía», equívoco referente que aparentemente alude a la concha bautismal, signo de inocencia primigenia, pero que a la vez es representación de la genitalidad femenina (Está la niña jugando, / blanca, rosa y desvestida, / sentada en el lecho junto / a una concha de agua pía). Por su parte, Dafnis se nos presenta, como en la obra de Longo, inserto en el debate entre su deseo de consumación sexual - representado en el laurel, símbolo de triunfo (Dafnis piensa en el laurel / que da la muerte y la vida,) y su adaptación a las todavía infantiles costumbres de su amada («mas con las jóvenes yemas/de sus dedos hace pinza/ en el fuego incoercible / de las frágiles cunitas»). El final de poema es una llamada al disfrute del amor en la más pura estela del carpe diem horaciano («En vuestros juegos pueriles / y adultos ya, daos prisa; / ¡veloces como la luz / van el amor y la dicha!»). En La casa mala, Bacarisse elabora poéticamente el encuentro furtivo de dos jóvenes, en los que la inocencia («la niña, casi una santa») y la juventud («rey de la vida era el mozo») nos remiten a los personajes de Longo, aun sin llamarlos por su nombre, y todo el mundo de la naturaleza se desplaza a los objetos circundantes («unas mariposas blancas / de oro tornan los balaustres / y florecen las persianas») («libélulas de la colcha, / moscas de las porcelanas, / enjambres del arambel / cigüeñas de las pantallas») y no falta la alusión a la sucesión de las estaciones, tema básico en la obra del de Lesbos, o la mención de la golondrina, motivo de uno de los más conocidos pasajes de Dafnis y Cloe: («Nieve y noche de los vuelos / ¿qué primavera anunciabais, / golondrinas de charol / junto al friso de la cama?»). El tercero de los poemas, Luna de Miel, descripción poética de una primera noche de amor, parece remitir al último pasaje de la novela de Longo, en el que los personajes llegan a culminar la unión sexual:

Dafnis y Cloe, a pesar de la música, se acostaron juntos desnudos; allí se abrazaron y se besaron, sin pegar los ojos en toda la noche, como lechuzas. Y Dafnis hizo a Cloe lo que le había enseñado Lycenia; y Cloe conoció por primera vez que todo lo hecho antes, entre las matas y en la gruta, no era más que simplicidad o niñería ${ }^{107}$.

En la misma tónica que el poema anterior, con desplazamiento del mundo de la naturaleza a los objetos inanimados («En la pantalla de china / hay doce abejas, grabadas»), se desarrolla el motivo del cambio radical producido por la

${ }^{107}$ Dafnis y Cloe, libro IV, traducción de Juan Valera. 
consumación del amor: «Colmena del alma mía, / colmena de atardecer; / tu luna, que era de cera, / por la mañana es de miel». La edición de estos poemas tuvo un gran éxito de crítica y Jorge Gillén felicitó por carta al poeta, más que por su triunfo en las oposiciones, por la calidad de su «Dafnis y Cloe»:

Pero yo quiero figurarme que el ejercicio decisivo para el tribunal Ideal ha debido ser el de «Dafnis y Cloe». ¡Qué bien!108.

Bacarisse incluirá estos tres poemas junto con otros dos más bajo el epígrafe de Dafnis y Cloe en su libro de poemas titulado Mitos (1930) con el que introduce el imaginario clásico en las nuevas tendencias poéticas del momento. $\mathrm{Su}$ temprana muerte no permitió que nos legara una obra más amplia en la que, seguramente, abundarían los elementos clásicos. Con él se termina la recreación de la figura de los amantes de Lesbos en la Edad de Plata de la cultura española. El intervalo de la Guerra Civil y los años que siguieron a la contienda no propiciaron especialmente la revisión de Dafnis y Cloe, si bien se siguió editando la traducción de Valera. La reivindicación de la novela de Longo tendrá ya lugar por parte de algún miembro del movimiento de los llamados Novísimos ${ }^{109}$ y la primera traducción moderna, hecha por un profesor de Griego, es la llevada a cabo por Máximo Brioso para la editorial Gredos en $1981^{110}$.

\section{AlgunAs CONCLUSIONES}

Parece evidente que la novela de Longo, a través de la traducción de Juan Valera, que la puso de moda, es la novela griega que mayor recepción ha tenido en las diversas corrientes literarias y artísticas de finales del XIX y principios del Xx. Dentro de la literatura realista y naturalista han citado y recreado las Pastorales autores de signo muy distinto y con intención muy diversa: Desde la admiración estética del conservador Palacio Valdés a la vuelta de tuerca naturalista que Emilia Pardo Bazán da al argumento de $D a$ fnis y Cloe en La Madre Naturaleza.

Mayor interés tiene el empleo interesado de Dafnis y Cloe por parte de la novela medico-social de López Bago, con intención programática y combativa. El extremo opuesto, pero no menos interesante, lo representa la moda literaria de ciertos autores de novela galante, como Jacinto Octavio Picón o José Ortega Munilla, de mencionar la obra de Longo, bien para comparar a la protagonista femenina, bien para incorporar la descripción de obras de arte en la

108 Carta inédita de 22 de mayo de 1926. La tomo de PÉREZ, Roberto. Ibid., p. 34.

109 Longo. Dafnis y Cloe: VALERA, Juan (trad. y pról.). VILLENA, Luis Antonio (est. prel.). Madrid: Ediciones Felmar, 1974.

${ }^{110}$ BRIOSO SÁNCHEZ, Máximo; CRESPO GÜEMES, Emilio (Intr., trad. y notas). Dafnis y Cloe / Longo. Leucipa y Clitofonte / Aquiles Tacio, Babiloníacas: (resumen de Focio $y$ fragmentos) / Jámblico. Madrid: Gredos, 1982. 
que están representados los pastorcillos lesbios, siguiendo claramente la estela de Valera, en su Pepita Jiménez.

Años después, la traducción indirecta de Dafnis y Cloe, hecha a través de la versión francesa, llevada a cabo por Carmen de Burgos, amén de pecar de carencia de bases filológicas e interpretativas, da cuenta de la consideración de las Pastorales en la época, al publicarse en una colección que lleva por título Clásicos del Amor, en la editorial Prometeo.

Cuestión aparte es la utilización puntual del tema de Dafnis y Cloe por algunos autores de la llamada novela lírica, en las que el narrador-autor expresa, en mayor o menor grado, sus ideas en torno a la sexualidad, tomando el referente clásico de los personajes de la novela del de Lesbos: Es el caso de la aversión a la novela de Longo mostrada explícitamente por Ángel Ganivet en Los Trabajos del infatigable creador Pío Cid, y reforzada por el contenido de sendos sonetos, en francés y en español, que sobre esta novela griega dejó escritos, y que no dejan de ser un reflejo literario de su complejo rechazo a la sexualidad. De forma menos traumática Ramón Pérez de Ayala y Gabriel Miró, utilizan las referencias y la trama de las Pastorales para describir el paso de la adolescencia a la edad adulta dentro, asimismo, de la novela lírica. En el caso de Pérez de Ayala, Dafnis y Cloe es el punto de partida para hacer una acerba crítica de la represión sexual del momento.

En el momento de esplendor final de la Edad de Plata, algunos escritores de la Generación del 27 conocieron y estimaron la obra de Longo e incluso la mencionaron con una función onírico-simbólica, mientras que Mauricio Bacarisse, buen conocedor de la lengua griega, deconstruyó los motivos principales de Dafnis y Cloe en su conjunto de poemas del mismo nombre, dando entrada a esta novela griega en la estética de la modernidad.

Pese a lo ajeno que debió de estar don Juan Valera acerca de la repercusión que la introducción del texto de Dafnis y Cloe en España iba a tener en las artes y las letras patrias, desde luego, acertó al afirmar que la novela de Longo presentaba «elementos de belleza absoluta y permanente en el tiempo», o al menos, según creemos, elementos lo suficientemente universales, como son el paso de la infancia a la adolescencia o la iniciación en el sexo, como para que, al margen de modas y corrientes estéticas, el autor moderno vuelva los ojos a este clásico para, mediante él, mostrar su postura ante un tema eternamente interesante y polémico.

Fecha de presentación: 4 de marzo de 2009

Fecha de aceptación: 2 de noviembre de 2009 